\title{
Parameter conditioning with a noisy Monte Carlo genetic algorithm for estimating effective soil hydraulic properties from space
}

\author{
Amor V. M. Ines ${ }^{1,2}$ and Binayak P. Mohanty ${ }^{1}$ \\ Received 17 April 2007; revised 12 May 2008; accepted 19 June 2008; published 27 August 2008.
}

[1] The estimation of effective soil hydraulic parameters and their uncertainties is a critical step in all large-scale hydrologic and climatic model applications. Here a scale-dependent (top-down) parameter estimation (inverse modeling) scheme called the noisy Monte Carlo genetic algorithm (NMCGA) was developed and tested for estimating these effective soil hydraulic parameters and their uncertainties. We tested our method using three case studies involving a synthetic pixel (pure and mixed) where all modeling conditions are known, and with actual airborne remote sensing (RS) footprints and a satellite RS footprint. In the synthetic case studies under pure (one soil texture) and mixed-pixel (multiple soil textures) conditions, NMCGA performed well in estimating the effective soil hydraulic parameters even with pixel complexities contributed by various soil types and land management practices (rain-fed/irrigated). With the airborne and satellite remote sensing cases, NMCGA also performed well for estimating effective soil hydraulic properties so that when applied in forward stochastic simulation modeling it can mimic large-scale soil moisture dynamics. The results also suggest a possible scaling down of the effective soil water retention curve $\theta(\mathrm{h})$ at the larger satellite remote sensing pixel compared with the airborne remote sensing pixel. However, it did not generally imply that all effective soil hydraulic parameters should scale down like the soil water retention curve. The reduction of the soil hydraulic parameters was most profound in the saturated soil moisture content $\left(\theta_{\text {sat }}\right)$ as we relaxed progressively the soil hydraulic parameter search spaces in our satellite remote sensing studies. Overall, the NMCGA framework was found to be very promising in the inverse modeling of remotely sensed near-surface soil moisture for estimating the effective soil hydraulic parameters and their uncertainties at the remote sensing footprint/climate model grid.

Citation: Ines, A. V. M., and B. P. Mohanty (2008), Parameter conditioning with a noisy Monte Carlo genetic algorithm for estimating effective soil hydraulic properties from space, Water Resour. Res., 44, W08441, doi:10.1029/2007WR006125.

\section{Introduction}

[2] Many hydrologic and hydroclimatic models used the soil water retention $\theta(\mathrm{h})$ and hydraulic conductivity $\mathrm{K}(\mathrm{h})$ functions for land-atmosphere interactions at the critical zone of the Earth surface [Kabat et al., 1997; Brantley et al., 2006]. The soil hydraulic functions, however, are based on pore/point-scale concepts generally described by a set of soil hydraulic parameters that are used to define the scale and shape of the soil hydraulic functions [Brooks and Corey, 1966; Campbell, 1974; Mualem, 1976; Van Genuchten, 1980; Leij et al., 1999]. Thus when the soil hydraulic functions are used to describe the average (soil) hydraulic behavior of a climate model grid or a remote sensing (RS)

\footnotetext{
${ }^{1}$ Department of Biological and Agricultural Engineering, Texas A\&M University, College Station, Texas, USA.

${ }^{2}$ Now at International Research Institute for Climate and Society, Earth Institute at Columbia University, Palisades, New York, USA
}

footprint, the estimation of the effective forms of the soil hydraulic parameters is extremely important [Feddes et al., 1993a; Wood, 1994; Vrugt et al., 2005]. The challenge is apparent, i.e., how to account for the effects of scale and heterogeneity of the study domain (e.g., at RS footprint/ climate model grid) into the derived effective soil hydraulic parameters [Feddes et al., 1993b; Mohanty and Skaggs, 2001; Zhu and Mohanty, 2002, 2003, 2004].

[3] In the past several decades, the similar media scaling of Miller and Miller [1956] had been widely used to account for the effect of scale when the point-scale soil hydraulic functions are used to describe the soil hydraulics of larger hydrologic domains [e.g., Hopmans and Stricker, 1989; Clausnitzer et al., 1992; Bertuzzi and Brucker, 1996; Rockhold et al., 1996; Jury et al., 1987; Van Dam et al., 1997; Droogers and Bastiaanssen, 2002]. In similar media scaling, a set of scaling factors is determined by relating the characteristic lengths of the smaller-scale porous media (from several point locations) with the characteristic length 
of the reference, geometrically equivalent, larger-scale porous medium [Miller and Miller, 1956; Clausnitzer et al., 1992]. The scaling factors are then used to upscale the point-scale soil water pressure heads and hydraulic conductivities to the reference soil hydraulic functions, i.e., the average soil hydraulic behavior of the reference porous medium. Also, an alternative method called the power law scaling had been proposed to upscale the point-scale soil hydraulic properties [Korvin, 1982; Gomez-Hernandez and Gorelick, 1989; Green et al., 1996]. With the power law scaling, the point-scale soil hydraulic parameters are aggregated into their average values using the most appropriate averaging technique (i.e., arithmetic, harmonic, or geometric based on prevailing soil hydrologic conditions) to arrive at the effective values of the soil hydraulic parameters [ $\mathrm{Zhu}$ and Mohanty, 2002, 2004, 2006]. For these scaling methods to perform effectively, an extensive amount of site-specific point-scale soil hydraulic data are required (as inputs), therefore limiting their applications in hydroclimatic modeling where such kinds of point-scale data are generally scarce.

[4] Recent studies suggest that the inversion of the average soil hydrologic variables, e.g., observed soil moisture and surface fluxes from remote sensing (RS), could be used to estimate the effective soil hydraulic parameters of large-scale hydrologic domains [e.g., Ines and Mohanty, 2008a; Feddes et al., 1993a, 1993b; Burke et al., 1998; Droogers and Bastiaanssen, 2002; see also A. V. M. Ines and B. P. Mohanty, Near-surface soil moisture assimilation for quantifying effective soil hydraulic properties using the genetic algorithm: 2. With air-borne remote sensing during SGP97 and SMEX02, submitted to Water Resources Research, 2008]. In connection to this, several studies also suggest that the average/aggregated soil hydrologic fluxes in a coarse-resolution RS pixel could reflect the effects of scale [Drusch et al., 1999; Zhu and Mohanty, 2002; Crow et $a l ., 2005]$ and heterogeneity of the spatial features contained within the pixel [Shimabukuro and Smith, 1991; Feddes et al., 1993a; Ines and Honda, 2005; Haertel and Shimabukuro, 2005; Chemin and Honda, 2006]. If this hypothesis is true, then the derived effective soil hydraulic parameters from the RS data inversion could somehow account for the effects of both the scale and heterogeneity of the pixel/ footprint under study.

[5] In line with this, many efforts have been made to study and understand the uncertainties of the effective soil hydraulic parameters within the effective modeling domain. Abbaspour et al. [1997] developed a sequential-uncertaintydomain-parameter-fitting (SUFI) scheme that fits the soil hydraulic parameters while sequentially threshing the uncertainty domains (prior to posterior) of each parameter considered. Subsequently, Abbaspour et al. [1999] introduced the concept of parameter conditioning (as opposed to parameter fitting) as a way of soil parameter estimation, which they define as the identification of a parameter domain so that when propagated in stochastic simulations, all or most of the measured points (i.e., the soil hydrologic variable) are within the $95 \%$ confidence interval (95PCI) of the Bayesian distribution of that parameter. A. V. M. Ines and B. P. Mohanty (submitted manuscript, 2008) also applied an inverse modeling (IM)-based near-surface soil moisture assimilation scheme to estimate the effective soil hydraulic parameters (and their uncertainties) of selected airborne remote sensing footprints/fields at Walnut Creek watershed, Iowa (SMEX02) and Little Washita watershed, Oklahoma (SGP97) [Bindlish, 2004; Jackson et al., 1999]. They developed a multipopulation ensemble genetic algorithm (GA) for the RS near-surface soil moisture assimilation and data inversion [Ines and Mohanty, 2008a, 2008b, submitted manuscript, 2008]. Zhu and Mohanty [2002, 2003, 2004] also examined the variability statistics (i.e., first, second, and third moments) of the effective soil hydraulic parameters (and scaling factors) at different hydrologic conditions based on the bottom-up approach (i.e., parameter aggregation from point to larger scale) for determining the effective soil hydraulic parameters. Among others, these above mentioned studies recognized the importance of parameter uncertainty analysis to reinforce further the concept of effective soil hydraulic parameters in defining large-scale hydrologic processes.

[6] Significant progress has been made in the development of robust parameter estimation techniques in the forms of evolutionary (e.g., genetic algorithm (GA) [Wang, 1991; Ines and Droogers, 2002; Ines and Mohanty, 2008a, submitted manuscript, 2008] and Shuffled Complex EvolutionUniversity of Arizona (SCE-UA) [Duan et al., 1992], among others) and Monte Carlo simulation techniques (e.g., Markov chain Monte Carlo (MCMC) [Kuczera and Parent, 1998; Bates and Campbell, 2001], Generalized Likelihood Uncertainty Estimation (GLUE) [Beven and Binley, 1992; Beven and Freer, 2001], and Shuffled Complex Evolution Metropolis-University of Arizona/Amsterdam (SCEM-UA) [Vrugt et al., 2003, 2005], among others). A relatively new breed of genetic algorithms called the noisy GAs (because they operate in noisy environment/ fitness function) had been also proposed for solving search and optimization problems under uncertainty [Miller and Goldberg, 1996; Miller, 1997]. The noisy GAs are generally used in the search of optimal remediation designs (considering risks and uncertainties) for impaired aquifers/groundwater systems [Smalley et al., 2000; Gopalakrishnan et al., 2003; Wu et al., 2006]. Because of its built-in capacity to estimate simultaneously the effective soil hydraulic parameters and their uncertainties, the noisy GA framework appears to be more robust and useful for the IM-based near-surface soil moisture assimilation problem [Ines and Mohanty, 2008a, submitted manuscript, 2008].

[7] In this study, we developed a method based on noisy GA for estimating the effective soil hydraulic parameters (and their uncertainties) at the satellite RS footprint scale and tested its performance using data from the Advanced Microwave Scanning Radiometer (AMSR-E) sensor (on the AQUA satellite) at a selected footprint in Iowa during the Soil Moisture Experiment 2005 (SMEX05) field campaign. The main assumption used in our scale-dependent parameter estimation concept is based on the idea that the effective forms of the soil hydraulic functions (at the RS footprint) can be inferred by the effective soil hydraulic parameters derived from large-scale RS soil moisture data inversion. In this study, along with the noisy GA framework, we also applied the concept of parameter conditioning [Abbaspour et al., 1999], which assumes that the simulated soil moistures should approximate and honor the observed RS footprint soil moisture data if the derived effective soil 


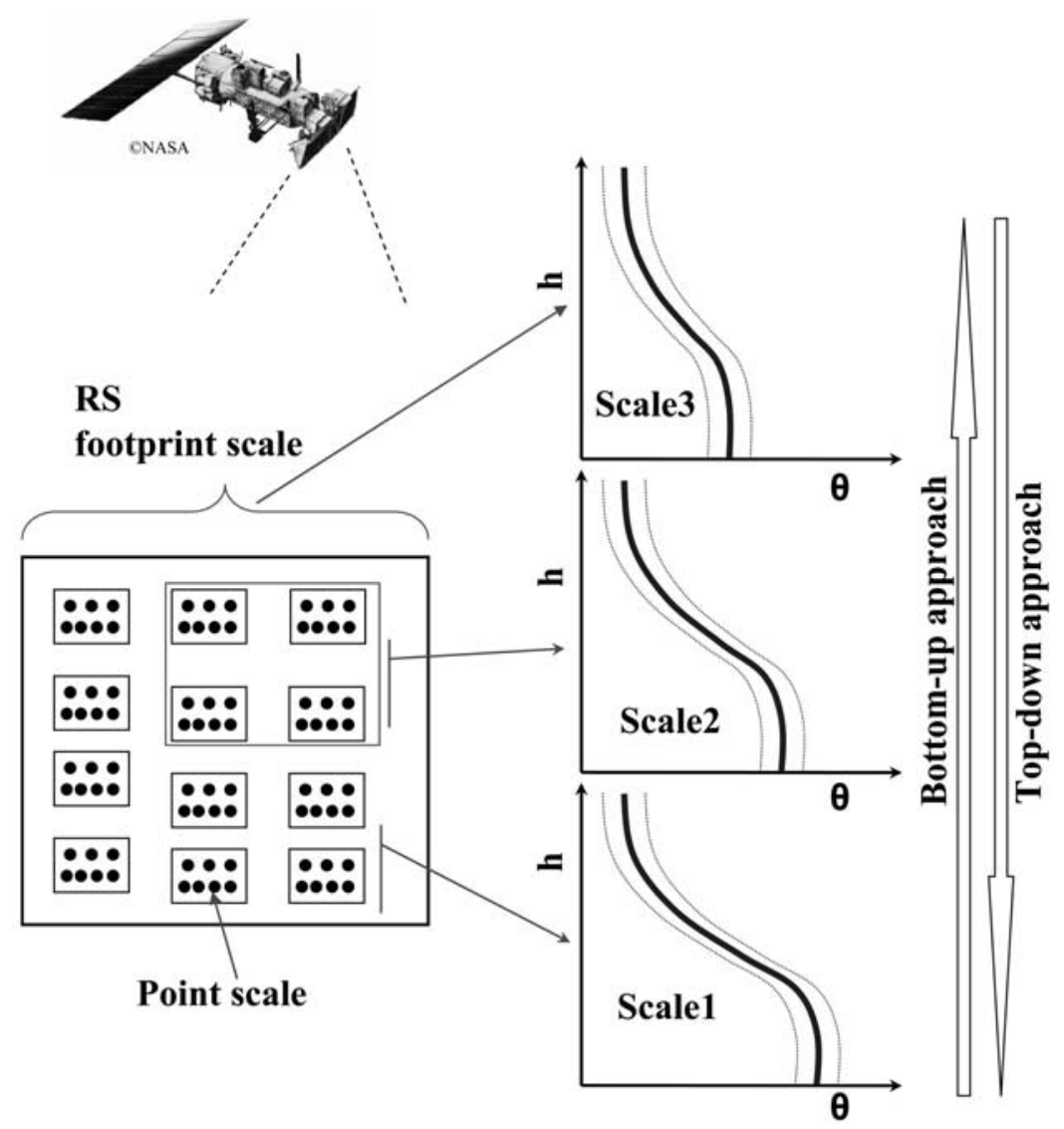

Figure 1. Hypothetical behavior of the effective soil hydraulic properties at different scales; h, pressure head $(\mathrm{cm}) ; \theta$, soil moisture $\left(\mathrm{cm}^{3} \mathrm{~cm}^{-3}\right)$.

hydraulic parameters and their uncertainties are propagated in stochastic/Monte Carlo simulations. We also tested the method using synthetic RS soil moisture data and actual airborne RS soil moisture data.

\section{Methods}

\subsection{Scaling the Soil Hydraulic Functions}

[8] The basis of our soil hydraulic function scaling hypothesis (i.e., the scale-dependent parameter estimation concept) is depicted in Figure 1, which shows a conceptual representation of the shape/form of the soil hydraulic function $\theta(\mathrm{h})$ at various spatial scales e.g., from scale 1 to scale 2 , from scale 2 to scale 3 , and vice versa. Scale 1 represents a parcel of land (composed of point-scale information), while scale 2 represents a larger parcel of land/ an airborne remote sensing (RS) footprint, e.g., polarimetric scanned radiometer (PSR) [Bindlish, 2004], and scale 3 represents the satellite RS footprint, e.g., AMSR-E [Njoku et al., 2003]. Scaling the soil hydraulic function from scale 1 to scale 3 is commonly known as the bottom-up approach [e.g., Zhu and Mohanty, 2002, 2003, 2004], while scaling it down from scale 3 to scale 1 is the so-called topdown approach [e.g., Ines and Mohanty, 2008a, submitted manuscript, 2008]. If this hypothesis is valid, we can readily develop some scaling relationships among the effective soil hydraulic functions (here $\theta(\mathrm{h}) \mathrm{s}$ ), and hence the effective soil hydraulic parameters, a scales (i.e., upscaling/down- scaling). These (possible) scaling functions/factors across scales could be determined if we can construct the effective soil hydraulic functions at those particular scales (Figure 1) using RS soil moisture data inversion by inverse modeling (i.e., by determining the scale/domain-dependent effective soil hydraulic parameters). This study will address the first step of the process by developing the method to derive the effective soil hydraulic parameters and their uncertainties at the airborne and satellite RS footprints.

\subsection{Noisy Monte Carlo Genetic Algorithm and RS Data Inversion}

[9] The main assumption used in the inverse modeling of RS near-surface soil moisture data is that the RS data contain (enough) information that can possibly describe the effective (soil) hydrologic conditions of a pixel, such that when inverted, it (i.e., the RS data) will provide a set of soil hydraulic parameters representative of that pixel. In this study, we developed a more general approach of a scaledependent parameter estimation concept (Figure 1) such that both the effective soil hydraulic parameters and their uncertainties could be determined simultaneously at a remote sensing footprint/climate model grid.

[10] The soil-water-atmosphere-plant (SWAP) model [Van Dam et al., 1997] as used in this study to model the soil moisture dynamics in a pixel uses the local-scale Mualem-van Genuchten constitutive models for defining the soil hydraulic functions $\theta(\mathrm{h})$ and $K(\mathrm{~h})$. Equations (1) and 
(2) describe the capability of a (particular) soil to retain, store, and transmit water under prevailing environmental conditions (i.e., inferred by pressure head $\mathrm{h}(-\mathrm{cm})$ ),

$$
\begin{gathered}
\mathrm{S}_{\mathrm{e}}=\frac{\theta(\mathrm{h})-\theta_{\text {res }}}{\theta_{\text {sat }}-\theta_{\text {res }}}=\left[\frac{1}{1+|\alpha \mathrm{h}|^{\mathrm{n}}}\right]^{\mathrm{m}} \\
\mathrm{K}(\mathrm{h})=\mathrm{K}_{\mathrm{sat}} \mathrm{S}_{\mathrm{e}}^{\lambda}\left[1-\left(1-\mathrm{S}_{\mathrm{e}}^{1 / \mathrm{m}}\right)^{\mathrm{m}}\right]^{2},
\end{gathered}
$$

where $\mathrm{S}_{\mathrm{e}}()$ is the relative saturation, $\alpha\left(\mathrm{cm}^{-1}\right)$ is a shape parameter equivalent to the inverse of the bubbling pressure, $\mathrm{n}(\mathrm{)}$ is a shape parameter that accounts for the pore size distribution, $\theta_{\text {res }}\left(\mathrm{cm}^{3} \mathrm{~cm}^{-3}\right)$ and $\theta_{\text {sat }}\left(\mathrm{cm}^{3} \mathrm{~cm}^{-3}\right)$ are scale parameters that stand for the residual and saturated soil moisture contents, $\mathrm{K}_{\mathrm{sat}}\left(\mathrm{cm} \mathrm{d}^{-1}\right)$ is another scale parameter that represents the saturated hydraulic conductivity, and $\lambda($ ) is a shape parameter that accounts for pore tortuosity in the soil. On the average, $\lambda$ has a value of 0.5 [Mualem, 1976]. Van Genuchten [1980] proposed $m$ to be equal to $1-1 / \mathrm{n}$. Hence the total set of soil hydraulic parameters in the Mualem-van Genuchten equations that can be subjected for parameter estimation by inversion of the one-dimensional (1-D) vertical flow equation (i.e., Richards' equation) in the soil profile is given as $\mathbf{k}=\left\{\alpha, \mathrm{n}, \theta_{\text {res }}, \theta_{\text {sat }}, \mathrm{K}_{\text {sat }}, \lambda\right\}$. Since the shape parameter $\lambda$ can be fixed (i.e., $\lambda=0.5$ ) in the implementation, A. V. M. Ines and B. P. Mohanty (submitted manuscript, 2008) determined the set of effective parameters $\mathbf{p}=\left\{\alpha, \mathrm{n}, \theta_{\text {res }}, \theta_{\text {sat }}, \mathrm{K}_{\text {sat }}\right\}$ (hence $\left.\mathbf{k}=\{\mathbf{p}, \lambda\}\right)$ for each study pixel (airborne remote sensing footprint) in their inverse analyses. In this study, the parameter set $\mathbf{p}$ was transformed into parameter set $\mathbf{p}^{*}=\left\{\alpha^{*}, \mathrm{n}^{*}, \theta_{\mathrm{res}}{ }^{*}, \theta_{\text {sat }}{ }^{*}\right.$, $\left.\mathrm{K}_{\mathrm{sat}}{ }^{*}\right\}$ (hence $\mathbf{k}=\left\{\mathbf{p}^{*}, \lambda\right\}$ ) to accommodate the uncertainty terms (e.g., analogous to horizontal heterogeneity in a pixel) of each parameter. The components of $\mathbf{p}^{*}$ are defined mathematically as

$$
\begin{gathered}
\alpha^{*} \sim \mathbb{N}\left(\mu_{\alpha}, \sigma_{\alpha}^{2}\right) \\
\mathrm{n}^{*} \sim \mathbb{N}\left(\mu_{\mathrm{n}}, \sigma_{\mathrm{n}}^{2}\right) \\
\theta_{\text {res }}^{*} \sim \mathbb{N}\left(\mu_{\theta_{\mathrm{res}}}, \sigma_{\theta_{\mathrm{res}}}^{2}\right) \\
\theta_{\mathrm{sat}}^{*} \sim \mathbb{N}\left(\mu_{\theta_{\mathrm{sat}}}, \sigma_{\theta_{\mathrm{sat}}}^{2}\right) \\
\mathrm{K}_{\mathrm{sat}}^{*} \sim \mathbb{N}\left(\mu_{\mathrm{K}_{\mathrm{sat}}}, \sigma_{\mathrm{K}_{\mathrm{sat}}}^{2}\right),
\end{gathered}
$$

where $\mathbb{N}$ ( ) represents the prior distribution assumed for each soil hydraulic parameter; $\left.\mu_{(}\right)$and $\sigma_{(\text {) }}$ are the first moments (means) and second moments (standard deviations) of the prior distributions proposed by genetic algorithm (described below).

[11] Genetic algorithms are powerful search techniques inspired by the mechanics of nature [Holland, 1975], and they combine the survival of the fittest mechanism among string structures (or chromosomes) with a structured yet randomized information exchange to solve any search/ optimization problem [Goldberg, 1989; Michalewicz, 1996]. In a binary GA the search spaces of the unknown parameters (e.g., the soil hydraulic parameters) are first discretized into finite lengths and then coded as a set of binary substrings to form a single string structure called a chromosome [see Ines and Mohanty, 2008a]. The arrangement of binary digits (i.e., 0s and 1s) in the chromosome represents a possible combination of the unknown parameters, which could be a possible solution to the problem. The search/optimization procedure starts by randomly generating a set of chromosomes (a population) to stage the initial search of the search surface, and since several chromosomes are included in a population, multiple starting positions are explored at the start of the search process. The chromosomes are then individually evaluated to determine their suitability (fitness) based on a prescribed fitness function (discussed later). Then they undergo the processes of reproduction by which they compete for selection (based on their fitness), crossover for genetic exchange resulting new chromosomes (offspring), and mutation to recover some genetic materials that were lost or diminished due to genetic drift. The processes of selection, crossover, and mutation are repeated for many generations until the best possible solution is achieved, which is basically the fittest chromosomes that have evolved after many generations. More detailed descriptions of GAs are given by Goldberg [1989].

[12] Noisy genetic algorithms (NGAs) are variants of GA that operate on a noisy fitness, which means that the chromosomes/decision variables are subjected to a stochastic field for (fitness) evaluation [Miller, 1997; Miller and Goldberg, 1996; Smalley et al., 2000; Gopalakrishnan et al., 2003; Wu et al., 2006]. In NGA the predefined parameter-field realizations are used as evaluation domains for a chromosome (i.e., proposed solution). The apparent fitness (per parameter field) of the chromosome are evaluated and then aggregated to arrive at the so-called chromosome "sampling fitness," which is used as a measure of the suitability of that chromosome against the given sets of parameter field. In this study, we extend the NGA framework to be able to evaluate the stochastic soil hydraulic parameters domains online using Monte Carlo simulations.

[13] Here we integrated a resampling algorithm [Efron, 1982] with GA for the Monte Carlo (MC) simulations of parameter fields. This was used to sample the chromosome $\mathbf{p}^{*}$ using the prior distributions of the effective soil hydraulic parameters (assumed to be normal a priori). In the newly integrated framework, a chromosome is evaluated as follows: First, GA proposes combinations of parameter statistics, and then based on these statistics MC dispenses realizations of parameter combinations. The generated combinations of effective soil hydraulic parameters for all the realizations made in one resampling event are used to evaluate the noisy fitness of the chromosomes along the generations. In this study, a number of ensembles or group of realizations (Figure 2b) was used to simulate the so-called "sampling fitness" (discussed below) of the stochastic chromosome $\mathbf{p}^{*}$. When the optimal/ near-optimal solution criterion is achieved, the statistics 

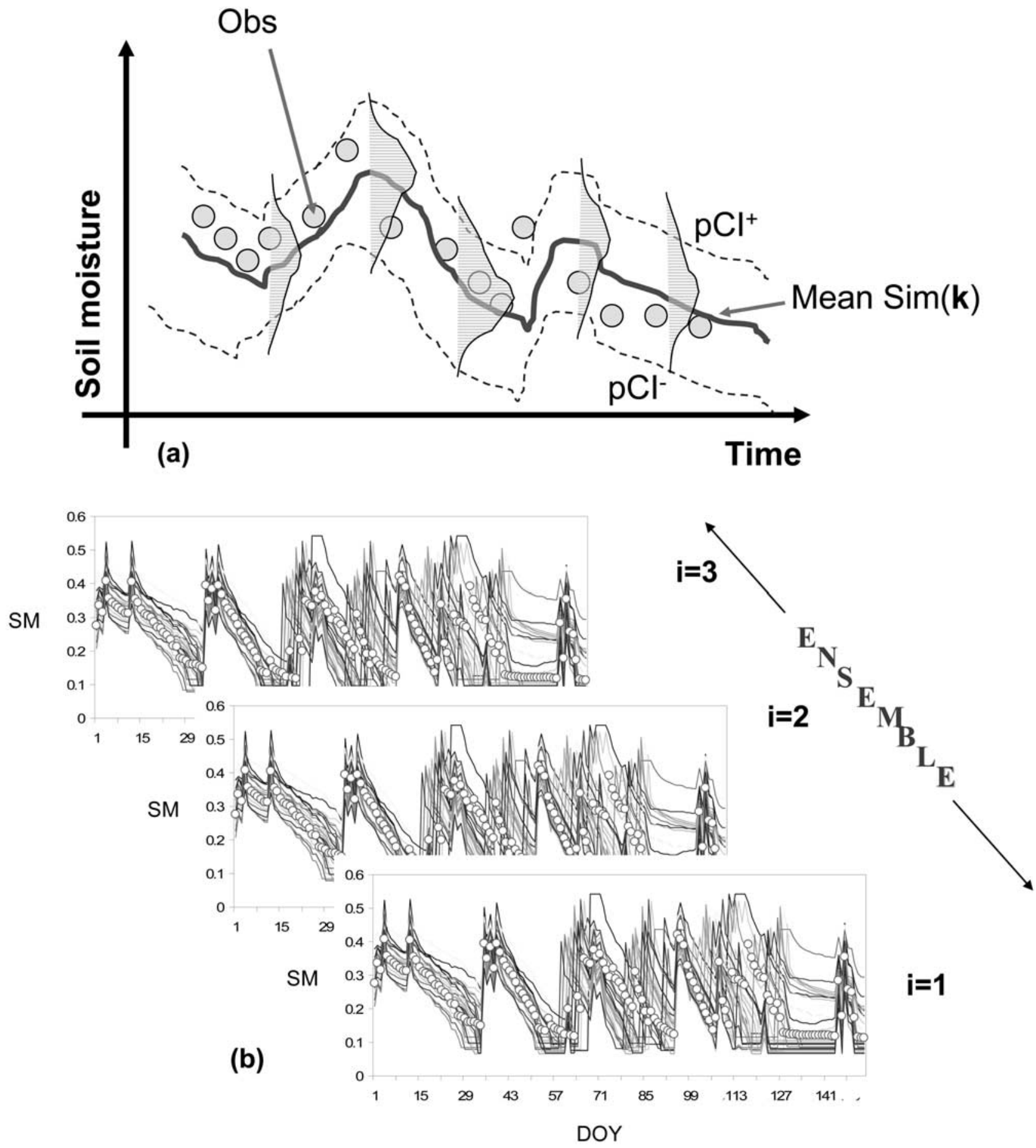

Figure 2. (a) Conceptual representation of simulated soil moisture using effective soil hydraulic parameters estimated from parameter conditioning (e.g., noisy Monte Carlo genetic algorithm (NMCGA)) showing the mean and spread of the simulated soil moistures approximately, and honoring the observed soil moisture data. (b) Ensembles of simulated soil moistures (SM) as a function of time (o, mean target values; traces, realizations of $\operatorname{Sim}\left(\mathbf{k}^{\mathrm{r}}\right)$ ).

(first and second moments including posterior distributions) of the effective soil hydraulic parameters derived from the $\mathrm{MC}$ resampling are considered to be the final solutions of the IM-based RS near-surface soil moisture assimilation problem. In this study, we used the maximum number of generations as our stopping criterion for all our noisy Monte Carlo genetic algorithm (NMCGA) applications.

[14] The chromosomal representation of $\mathbf{p}^{*}$ as used in this study is given by $\left\{\boldsymbol{\mu}_{(\alpha)}, \sigma_{(\alpha)}, \boldsymbol{\mu}_{(\mathrm{n})}, \sigma_{(\mathrm{n})}, \boldsymbol{\mu}_{(\theta \mathrm{res})}, \sigma_{(\theta \mathrm{res})}, \boldsymbol{\mu}_{(\theta \mathrm{sat})}\right.$, $\left.\boldsymbol{\mu}_{(\theta \mathrm{sat})}, \sigma_{(\theta \mathrm{sat})}, \boldsymbol{\mu}_{(\text {Ksat })}, \sigma_{(\text {Ksat })}\right\}$, whose binary representations 
Table 1. Representations of the Mualem-Van Genuchten Parameters in the Noisy Monte Carlo Genetic Algorithm (NMCGA) ${ }^{\mathrm{a}}$

\begin{tabular}{|c|c|c|c|c|c|c|c|c|c|c|}
\hline \multirow[b]{2}{*}{ Parameter } & \multicolumn{2}{|c|}{ Cases 1 and 2} & \multicolumn{2}{|c|}{ Case 3a } & \multicolumn{2}{|c|}{ Case $3 b$} & \multicolumn{2}{|c|}{ Case $3 c$} & \multirow[b]{2}{*}{$\begin{array}{c}\text { Number of } \\
\text { Bits (L) }\end{array}$} & \multirow[b]{2}{*}{$2^{\mathrm{L}}$} \\
\hline & $\begin{array}{l}\text { Minimum } \\
\text { Values }\end{array}$ & $\begin{array}{l}\text { Maximum } \\
\text { Values }\end{array}$ & $\begin{array}{l}\text { Minimum } \\
\text { Values }\end{array}$ & $\begin{array}{l}\text { Maximum } \\
\text { Values }\end{array}$ & $\begin{array}{l}\text { Minimum } \\
\text { Values }\end{array}$ & $\begin{array}{l}\text { Maximum } \\
\text { Values }\end{array}$ & $\begin{array}{l}\text { Minimum } \\
\text { Values }\end{array}$ & $\begin{array}{c}\text { Maximum } \\
\text { Values }\end{array}$ & & \\
\hline \multicolumn{11}{|c|}{ GA Variables } \\
\hline$\mu_{(\alpha)}\left(\mathrm{cm}^{-1}\right)$ & 0.006 & 0.033 & 0.006 & 0.033 & 0.006 & 0.033 & 0.006 & 0.1 & 5 & 32 \\
\hline$\sigma_{(\alpha)}\left(\mathrm{cm}^{-1}\right)$ & 0 & 0.033 & 0 & 0.033 & 0 & 0.033 & 0 & 0.1 & 5 & 32 \\
\hline$\mu_{(\mathrm{n})}()$ & 1.2 & 1.61 & 1 & 1.61 & 1 & 1.8 & 1 & 1.8 & 6 & 64 \\
\hline$\sigma_{(\mathrm{n})}()$ & 0 & 0.8 & 0 & 1 & 0 & 1 & 0 & 1 & 6 & 64 \\
\hline$\mu_{(\theta \mathrm{res})}\left(\mathrm{cm}^{3} \mathrm{~cm}^{-3}\right)$ & 0.061 & 0.163 & 0.061 & 0.163 & 0.061 & 0.163 & 0.002 & 0.2 & 7 & 128 \\
\hline$\sigma_{(\theta \mathrm{res})}\left(\mathrm{cm}^{3} \mathrm{~cm}^{-3}\right)$ & 0 & 0.02 & 0 & 0.3 & 0 & 0.3 & 0 & 0.3 & 7 & 128 \\
\hline$\mu_{(\theta \text { sat })}\left(\mathrm{cm}^{3} \mathrm{~cm}^{-3}\right)$ & 0.37 & 0.55 & 0.37 & 0.55 & 0.37 & 0.55 & 0.28 & 0.55 & 5 & 32 \\
\hline$\sigma_{(\theta \text { sat })}\left(\mathrm{cm}^{3} \mathrm{~cm}^{-3}\right)$ & 0 & 0.2 & 0 & 0.3 & 0 & 0.3 & 0 & 0.3 & 5 & 32 \\
\hline$\mu_{\text {(Ksat) }}\left(\mathrm{cm} \mathrm{d}^{-1}\right)$ & 1.84 & 55.7 & 1.84 & 55.7 & 2 & 60 & 1 & 60 & 10 & 1024 \\
\hline$\sigma_{\text {(Ksat) }}\left(\mathrm{cm} \mathrm{d}^{-1}\right)$ & 0 & 10 & 0 & 20 & 0 & 20 & 0 & 20 & 10 & 1024 \\
\hline \multicolumn{11}{|c|}{ MC Variables } \\
\hline$\alpha\left(\mathrm{cm}^{-1}\right)$ & 0.006 & 0.033 & 0.0001 & 1 & 0.0001 & 1 & 0.0001 & 1 & & \\
\hline $\mathrm{n}()$ & 1.2 & 1.61 & 1 & 1.95 & 1 & 1.95 & 1 & 1.95 & & \\
\hline$\theta_{\text {res }}\left(\mathrm{cm}^{3} \mathrm{~cm}^{-3}\right)$ & 0.061 & 0.163 & 0.001 & 0.25 & 0.001 & 0.25 & 0.001 & 0.25 & & \\
\hline$\theta_{\text {sat }}\left(\mathrm{cm}^{3} \mathrm{~cm}^{-3}\right)$ & 0.37 & 0.55 & 0.28 & 0.6 & 0.28 & 0.6 & 0.28 & 0.6 & & \\
\hline $\mathrm{K}_{\mathrm{sat}}\left(\mathrm{cm} \mathrm{d}^{-1}\right)$ & 1.84 & 55.7 & 1 & 80 & 1 & 80 & 1 & 80 & & \\
\hline
\end{tabular}

${ }^{\mathrm{a}}$ Global search space $=32 \times 32 \times 64 \times 64 \times 128 \times 128 \times 32 \times 32 \times 1024 \times 1024=7.3787 \mathrm{E}+19$. Example of p* $=\left\{\mu_{\alpha}, \sigma_{\alpha}, \mu_{\mathrm{n}}, \sigma_{\mathrm{n}}, \mu_{\theta \text { res }}, \sigma_{\theta \mathrm{res}}, \mu_{\theta \text { sat }}\right.$, $\left.\sigma_{\theta \text { sat }}, \mu_{\text {Ksat, }} \sigma_{\text {Ksat }}\right\}$; say, $\mathbf{p}^{*}=\{00101,00101,110010,110010,0001111,0001111,00001,00001,0101000101,0101000101\}$.

are given in Table 1. The objective function was conceptually formulated as

$$
\operatorname{Obj}(\mathbf{k})_{\mathrm{i}}=\operatorname{Min}\left(\frac{1}{\mathrm{~T}} \sum_{\mathrm{t}=1}^{\mathrm{T}}\left|\frac{1}{\mathrm{~N}_{\text {resample }}}\left(\sum_{\mathrm{r}=1}^{\mathrm{N}_{\text {resample }}} \operatorname{Sim}\left(\mathbf{k}^{\mathrm{r}}\right)_{\mathrm{ti}}\right)-\mathrm{Obs}_{\mathrm{t}}\right|\right) \forall \mathrm{i}
$$

for the $i$ th ensemble (Figure 2b). Note that $\mathbf{k}^{\mathrm{r}}$ means a set of $\mathbf{k}$ combinations with $\mathbf{r}$ realizations, i.e., the combinations of effective soil hydraulic parameters generated from $\mathrm{MC}$ resampling; $\mathrm{N}_{\text {resample }}$ is the number of samples (realizations) drawn from the each resampling; $\operatorname{Sim}\left(\mathbf{k}^{r}\right)$ stands for the simulated soil moisture given $\mathbf{k}=\left\{\mathbf{p}^{*}, \lambda\right\}$ at realization $\mathbf{r}$; Obs stands for the observed RS soil moisture data; and $\mathrm{t}$ is the running index for time $\mathrm{T}$. The optimization problem is subject to

$$
\begin{aligned}
\operatorname{Constr}(\mathbf{k})_{\mathrm{ti}}= & \left(\mathrm{Obs}_{\mathrm{t}}<\mathrm{PCI}^{+}\left(\operatorname{Sim}\left(\mathbf{k}^{\mathrm{r}}\right)\right)_{\mathrm{ti}}\right) \text { AND } \\
& \left(\mathrm{Obs}_{\mathrm{t}}>\mathrm{PCI}^{-}\left(\operatorname{Sim}\left(\mathbf{k}^{\mathrm{r}}\right)\right)_{\mathrm{ti}}\right) \forall \mathrm{t}(\text { where } \mathrm{t} \leq \mathrm{T}), \forall \mathrm{i}
\end{aligned}
$$

where

$$
\begin{gathered}
\mathrm{PCI}^{+/-}\left(\operatorname{Sim}\left(\mathbf{k}^{\mathrm{r}}\right)\right)_{\mathrm{ti}}=\frac{1}{\mathrm{~N}_{\text {resample }}} \sum_{\mathrm{r}=1}^{\mathrm{N}_{\text {resample }}} \operatorname{Sim}\left(\mathbf{k}^{\mathrm{r}}\right)_{\mathrm{ti}}+/-(\text { PCIfactor }) \mathbf{x} \\
\sqrt{\frac{\sum_{\mathrm{r}=1}^{\text {Nresample }}\left(\operatorname{Sim}\left(\mathbf{k}^{\mathrm{r}}\right)_{\mathrm{ti}}-\left(\frac{1}{\mathrm{~N}_{\text {resample }}} \sum_{\mathrm{r}=1}^{\mathrm{N}_{\text {resample }}} \operatorname{Sim}\left(\mathbf{k}^{\mathrm{r}}\right)_{\mathrm{ti}}\right)\right)^{2}}{\left(\mathrm{~N}_{\text {resample }}-1\right)}}
\end{gathered}
$$

$\forall \mathrm{t}($ where $\mathrm{t} \leq \mathrm{T}), \forall \mathrm{i}$

where Constr(k) stands for the logical constraint and PCIfactor indicates the confidence interval (i.e., PCIfactor $=1.96$ at $\mathrm{PCI}^{+/-}=95 \%$ ).

[15] Equation (9) suggests that the simulated soil moisture $\mathrm{MC}$ spectrum (from the re ing of $\mathbf{k}$ ) should honor the observed soil moisture (from airborne/satellite RS) at prescribed percent confidence interval (PCI) while the central tendency of the former approximates the latter (equation (8)) as depicted in Figure 2a.

[16] The fitness function, which is used to measure the suitability of $\mathbf{p}^{*}$, was defined using the modified-penalty approach of Chan-Hilton and Culver [2000] and was formulated as follows:

$$
\begin{gathered}
\mathrm{Z}(\mathbf{k})_{\mathrm{i}}=\left(\operatorname{Obj}(\mathbf{k})_{\mathrm{i}}\right) \times\left(1+\operatorname{Penalty}(\mathbf{k})_{\mathrm{i}}\right) \forall \mathrm{i} \\
\text { fitness }\left(\mathbf{p}^{*}\right)_{\mathrm{i}}=\frac{1}{\mathrm{Z}(\mathbf{k})_{\mathrm{i}}} \quad \forall \mathrm{i} .
\end{gathered}
$$

[17] Since $\mathbf{k}^{\mathrm{r}}$ is highly stochastic, the apparent (at that instance) fitness (equation (12)) of a chromosome p* (recall, $\mathbf{k}=\left\{\mathbf{p}^{*}, \lambda\right\}$ ) for each ensemble $i$ is not guaranteed to be similar for each (online) $\mathrm{MC}$ resampling event. By virtue of the central limit theorem, we minimize this high noise of the apparent fitness by calculating the so-called sampling fitness (Sfitness $\left(\mathbf{p}^{*}\right)$ ), by averaging the apparent fitness (equation (12)) of each ensemble $i$ from the $\mathrm{MC}$ resampling,

$$
\operatorname{Sfitness}\left(\mathbf{p}^{*}\right)=\frac{1}{\mathrm{R}} \sum_{\mathrm{i}=1}^{\mathrm{R}} \text { fitness }\left(\mathbf{p}^{*}\right)_{\mathrm{i}}
$$

where $\mathrm{R}$ is the total number of ensemble $i$ used in the chromosome evaluation (i.e., the number of $\mathrm{MC}$ resampling events). Penalty(k) (equation (11)) was determined by evaluating the right-hand side (RHS) of equation (9) if it is true or false. If equation (9) is false, then

$$
\begin{aligned}
& \operatorname{Penal}(\mathbf{k})_{\mathrm{ji}}=\sum_{\mathrm{t}=1}^{\mathrm{T}} \lambda_{\mathrm{tj}}\left(\mathrm{Obs}_{\mathrm{t}}-\mathrm{PCI}_{\mathrm{j}}\left(\operatorname{Sim}\left(\mathbf{k}^{\mathrm{r}}\right)\right)_{\mathrm{ti}}\right)^{2} \forall \mathrm{i} \\
& \text { for } \mathrm{j}=1\left(\mathrm{PCI}^{+}\right), 2\left(\mathrm{PCI}^{-}\right)
\end{aligned}
$$



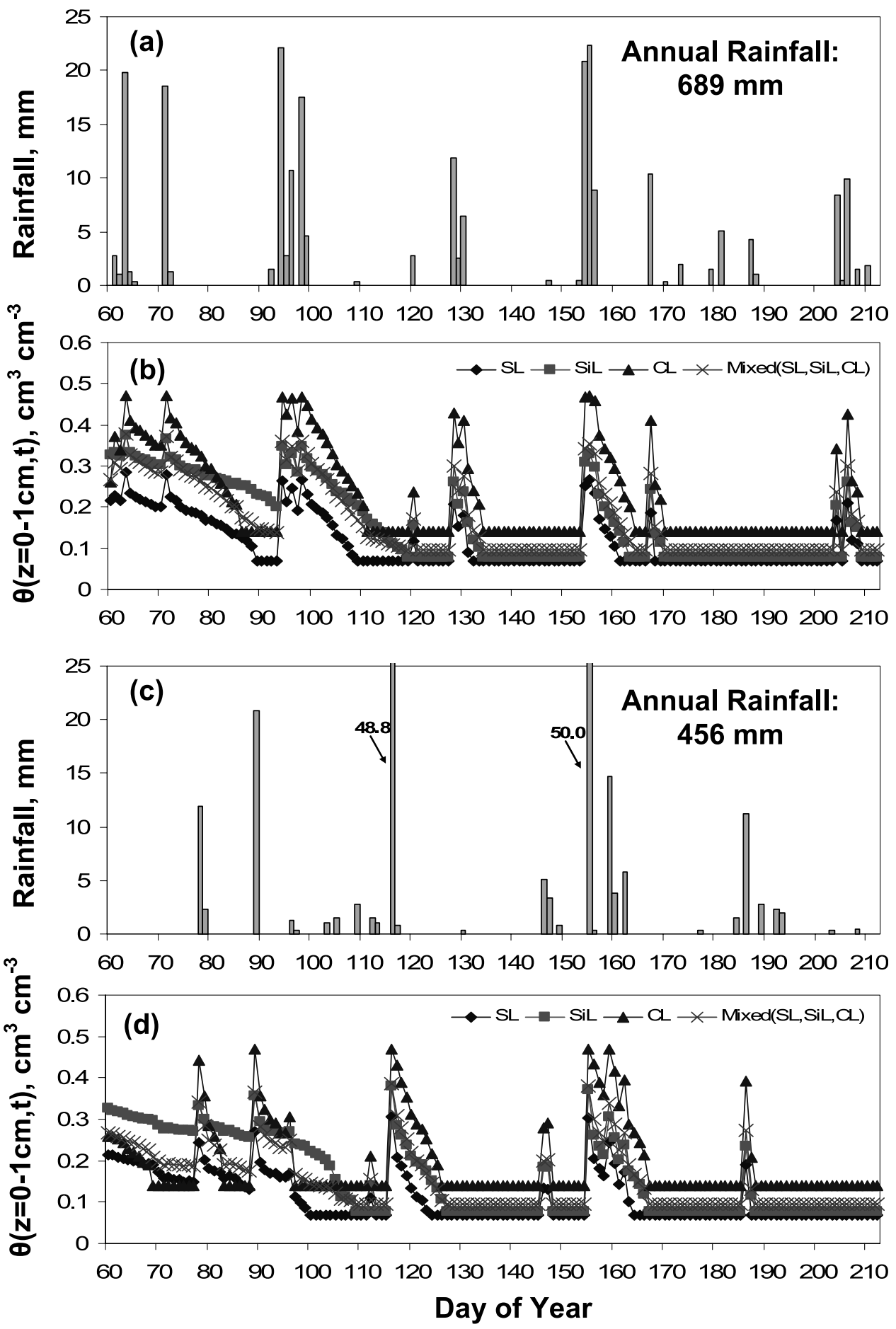

Figure 3. Synthetic rain-fed soil moistures generated for (b) wet, (d) relatively wet, and (f) dry year conditions used in the numerical experiments; (a) wet year seasonal rainfall, (c) relatively wet year seasonal rainfall, and (e) dry year seasonal rainfall in Lubbock, Texas. Pure pixels: SL, sandy loam; SiL, silt loam; CL, clay loam. Mixed pixel condition: SL,SiL,CL (0.33SL + 0.33SiL + 0.33CL).

where the penalty coefficient

$$
\lambda_{\mathrm{tj}}=\left\{\begin{array}{l}
10, \text { if the RHS of }(9) \text { is false } \\
0, \text { otherwise }
\end{array}\right.
$$

$$
\forall \mathrm{j}, \forall \mathrm{t}
$$

[18] Then

$$
\operatorname{Penalty}(\mathbf{k})_{\mathrm{i}}=\sum_{\mathrm{j}=1}^{2} \operatorname{Penal}(\mathbf{k})_{\mathrm{ji}} \forall \mathrm{i}
$$




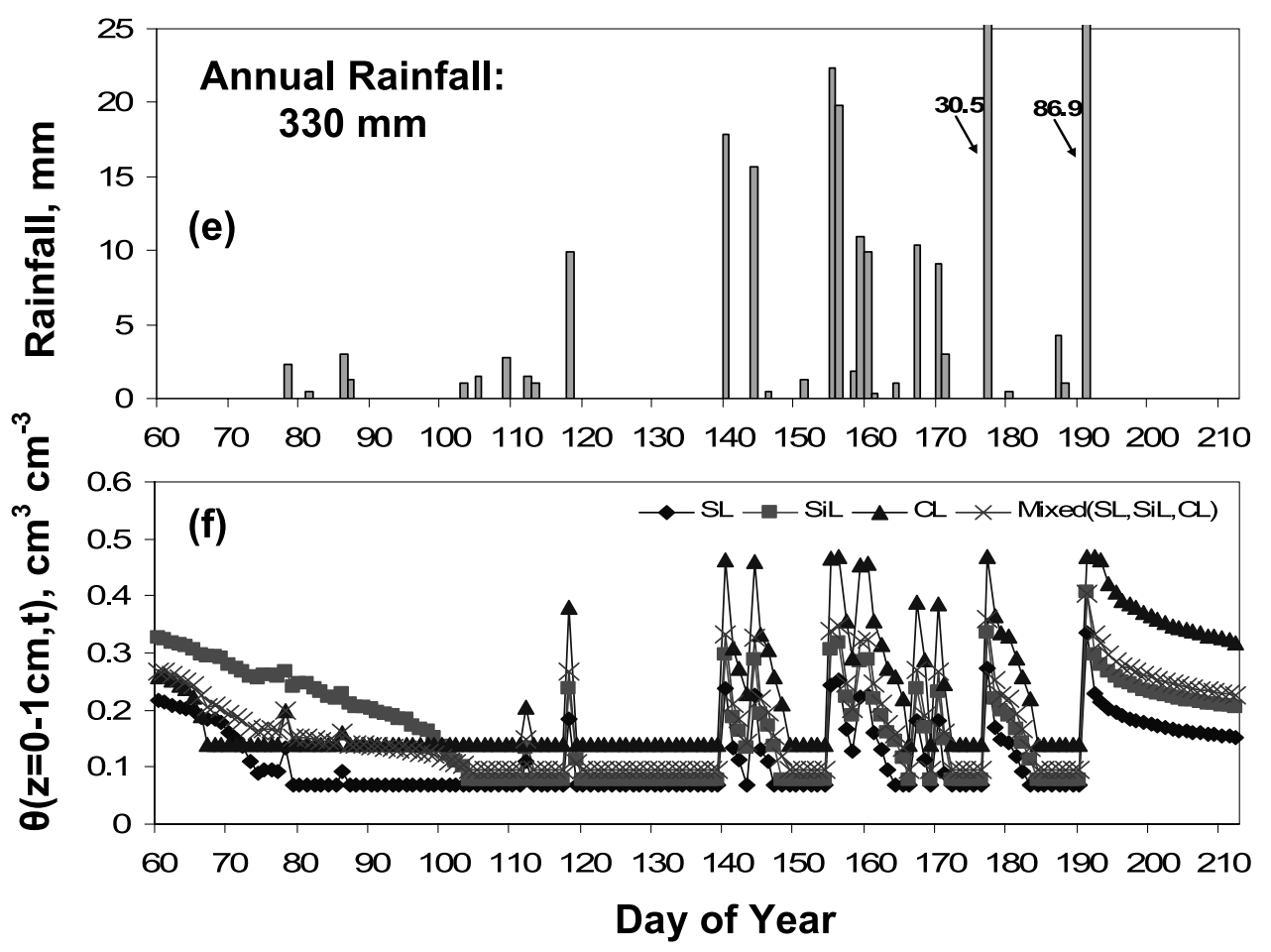

Figure 3. (continued)

[19] We implemented the above concepts for the IM-based near-surface soil moisture assimilation problem and extended the modified-microGA framework [Ines and Droogers, 2002; Ines and Honda, 2005; Ines and Mohanty, 2008a] (see also http://www.cuaerospace.com/carroll/ga.html). The new framework is called the noisy Monte Carlo genetic algorithm (NMCGA).

\subsection{Case Studies}

[20] In this study, three major case studies were conducted to test the newly developed NMCGA including case 1 , a numerical evaluation that involved solving the effective soil hydraulic parameters (and uncertainties) in a synthetic remote sensing (RS) pixel with one (pure) or more (mixed) soil textures (Figure 3); case 2, involving the use of an airborne RS soil moisture data as conditioning criteria; and case 3, involving the use of satellite RS soil moisture data in the inverse analysis.

\subsubsection{Numerical Evaluations}

[21] Using forward (SWAP) simulations, we generated hypothetical near-surface $(\sim 0-1 \mathrm{~cm})$ soil moisture data for three pure pixels containing sandy loam (SL), silt loam (SiL), and clay loam (CL) soils for wet, relatively wet, and dry years under rain-fed and irrigated conditions (Figures 3a-3c, Figure 4d). The mean soil hydraulic parameters for each soil type were taken from the UNSODA database [Leij et al., 1999]. From the generated soil moisture signatures we also derived mixed soil moisture signatures for mixed pixel conditions depending on the area fractions of soil types contained within a pixel (Figures $3 a-3 c$, Figure 4d). In each pixel considered, the soil depth was assumed to be $200 \mathrm{~cm}$ with wheat (Triticum aestivum) as land cover. Under irrigated conditions, irrigation was made automatically by SWAP according to an irrigation schedul- ing criterion based on the water stress level allowed to the crops (Figures $4 a-4 c)$. If this water stress level $\left(1-T_{\text {act }} / T_{\text {pot }}\right)$ exceeds the given threshold (here we used $\mathrm{T}_{\text {act }} / \mathrm{T}_{\text {pot }} \geq 0.70$ ), SWAP applies $100 \mathrm{~mm}$ of water via a surface irrigation, where $T_{\text {pot }}$ and $T_{\text {act }}$ stand for potential and actual transpiration. On conditions where oxygen $\left(\mathrm{O}_{2}\right)$ stress occurs due to soil over saturation, the model does not apply irrigation (Figure 4c) (note, however, that the unusual irrigation scheduling observed in the clay loam soil is due to the consequence or weakness of the automatic irrigation approach in SWAP). All the SWAP simulations were made across the crop growing season in Lubbock, Texas, from 1 March to 31 July (days of year (DOY) 60-212). The soil units were assumed to have free-draining bottom boundaries with wet initial conditions $(\mathrm{h}(\mathrm{z}, \mathrm{t}=0)=-100 \mathrm{~cm})$.

[22] In the NMCGA testing, the first scenario (case 1a) involved a pure pixel case (here we analyzed only the wetyear condition) where the effective soil hydraulic parameters and their uncertainties were estimated for each of the considered soil types using the simulated soil moisture signatures as conditioning data, under rain-fed and irrigated conditions (Figure 3a, Figure 4d). The second scenario (case 1b) is a mixed-pixel case where the mixed soil moisture signatures (Figures 3a-3c, Figure 4d) for each mixed pixel considered were used as conditioning data to estimate the effective soil hydraulic parameters (and their uncertainties), also under rain-fed and irrigated conditions. These numerical experiments were performed to test the effectiveness of the NMCGA under idealized conditions.

\subsubsection{Using Remote Sensing Soil Moisture}

[23] For the airborne remote sensing test (case 2), 10 (temporal) polarimetric scanned radiometer (PSR) soil moisture data sets [Bindlish, 2004] from the SMEX02 region (Figure 5) were used for our analysis (http://nsidc.org/). The 

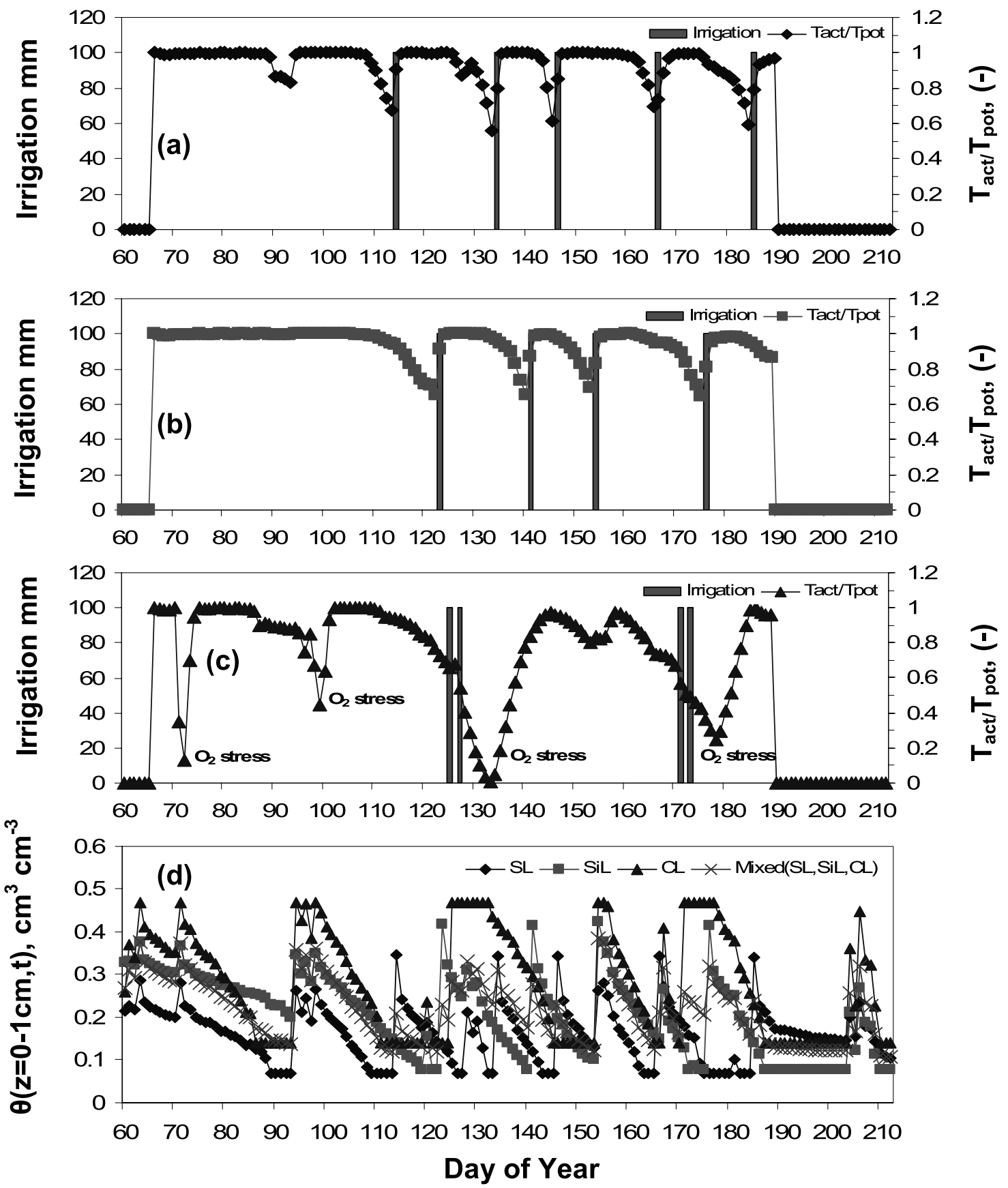

Figure 4. Sample target mean irrigation scheduling and relative transpiration used in the numerical experiments, for pure pixel (a) sandy loam (SL), (b) silt loam (SiL), and (c) clay loam (CL) soils under wet year condition, and (d) the corresponding generated synthetic irrigated soil moisture data used in IM including data for a mixed-pixel condition (SL, SiL, CL).

PSR-based soil moisture data have $800 \mathrm{~m} \times 800 \mathrm{~m}$ footprint/pixel resolution. The simulation soil units were assumed to be $2 \mathrm{~m}$ deep with corn as the dominant crop for fields WC11 and WC12, and soybean for fields WC13 and WC14 (Figure 5a). At this resolution, variable water table depths of 200, 150, and $100 \mathrm{~cm}$ were used as bottom boundary conditions. The soil units were initialized in equilibrium with the three water table depth scenarios. At the end of the NMCGA runs, the solutions from all three water table depth scenarios were collected to form the final solutions of the airborne-RS IM problem (A. V. M. Ines and B. P. Mohanty, submitte uscript, 2008).
[24] In case 3, NMCGA was tested on 1-year time series of Aqua satellite-borne AMSR-E soil moisture data $(\sim 25 \mathrm{~km}$ resolution) encompassing the Walnut Creek watershed during the SMEX05 campaign (Figure 5b, Figure 6b) (http://nsidc.org/). At this resolution, satellite-based vegetation and precipitation data, e.g., Moderate Resolution Imaging Spectroradiometer leaf area index (MODIS-LAI) and Tropical Rainfall Measuring Mission (TRMM) precipitation data (Figures 6a and 6b) were used as SWAP model inputs (http://disc.sci.gsfc.nasa.gov/). These data were aggregated and resampled based on AMSR-E resolution. The other meteorological data including daily maximum 


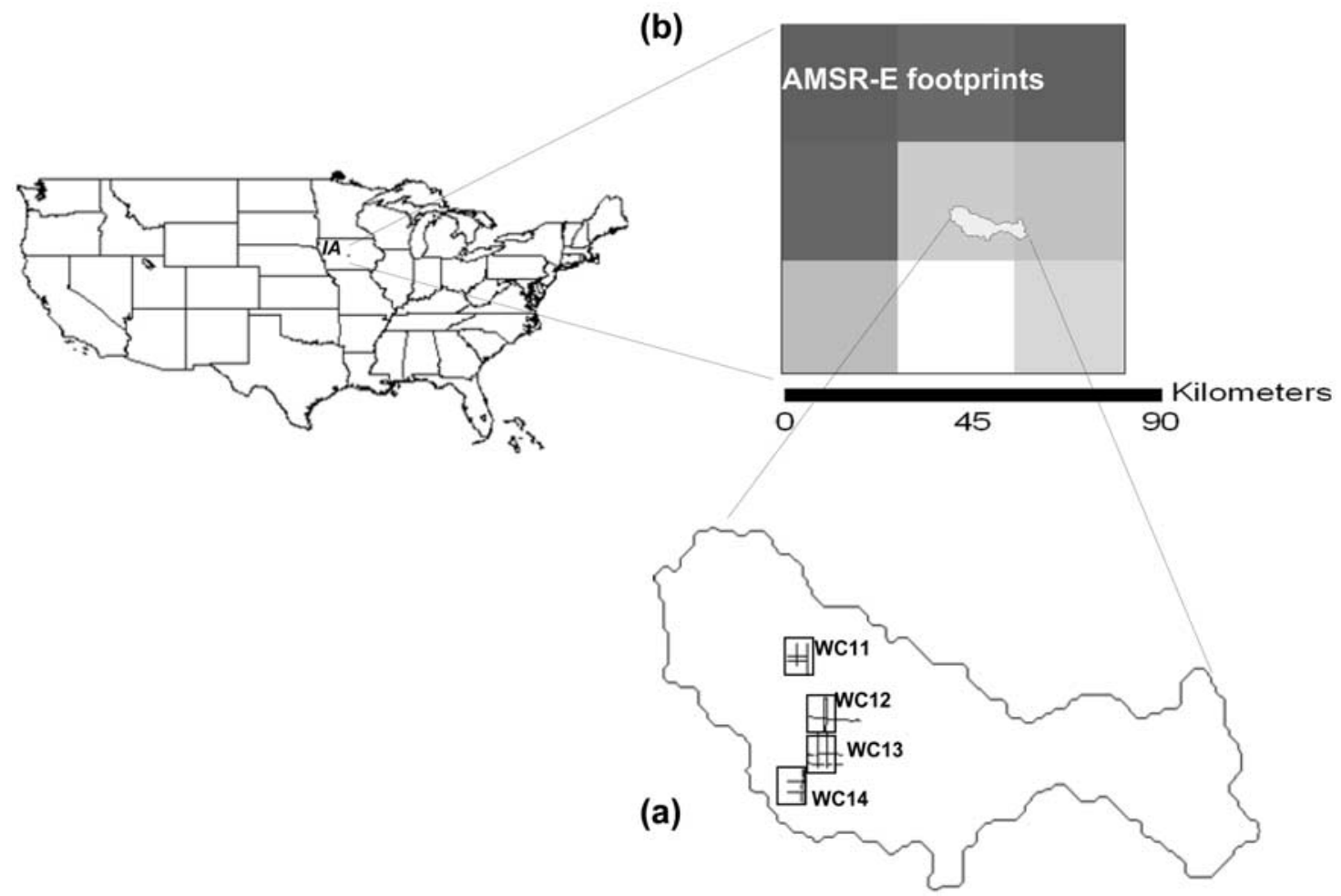

Figure 5. (a) Locations of the selected Walnut Creek watershed (WC) fields, Iowa, used for the airborne RS (PSR) analysis. (b) Inset of an AMSR-E pixel selected for the satellite RS analysis.

and minimum temperatures, solar radiation, wind speed, and air humidity were collected from the nearby SCAN weather station at Ames, Iowa (http://www.wcc.nrcs.usda.gov/). The SCAN site is situated within the AMSR-E pixel under study and about $5 \mathrm{~km}$ northwest of WC11 field (we used the same meteorological data in our modeling studies at WC fields).

[25] Three scenarios were evaluated when using satelliteborne AMSR-E soil moisture data for determining the effective soil hydraulic parameters and their uncertainties.
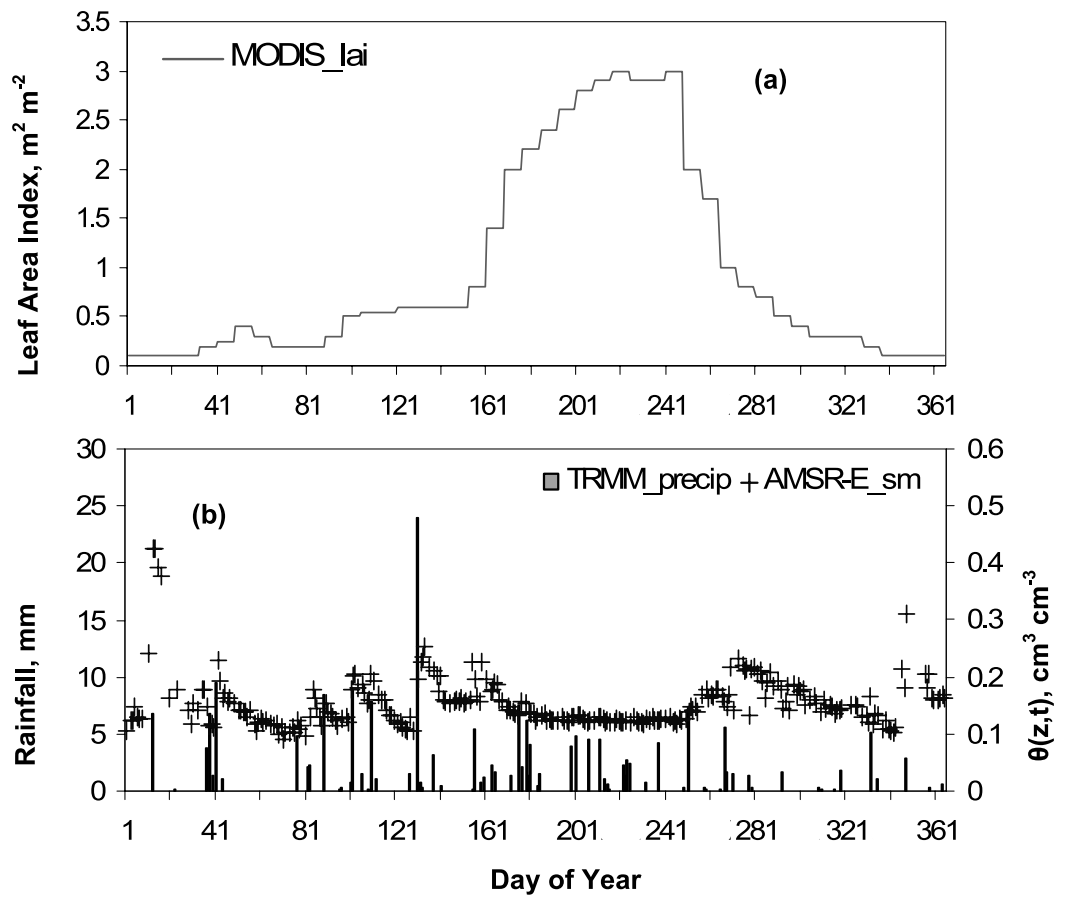

Figure 6. Time series (year 2005) of (a) MODIS-LAI and (b) TRMM-precipitation and AMSR-E nearsurface soil moist $\approx 0-1 \mathrm{~cm})$ used in the IM-based near-surface soil moisture assimilation. 
Table 2. Summary of Performance $\left(\mathrm{R}()\right.$ and $\left.\mathrm{MBE}\left(\mathrm{cm}^{3} \mathrm{~cm}^{-3}\right)\right)$ of the NMCGA in Replicating the Target Near-Surface $(\mathrm{z}=0-1 \mathrm{~cm})$ Soil Moisture for the Hypothetical RS Pixels ${ }^{\mathrm{a}}$

\begin{tabular}{|c|c|c|c|c|c|c|c|c|}
\hline \multirow[b]{3}{*}{ Soils } & \multicolumn{4}{|c|}{ Irrigated Condition } & \multicolumn{4}{|c|}{ Rain-Fed Condition } \\
\hline & \multicolumn{2}{|c|}{ Target Versus NMCGA } & \multicolumn{2}{|c|}{ Target Versus Weighted } & \multicolumn{2}{|c|}{ Target Versus NMCGA } & \multicolumn{2}{|c|}{ Target Versus Weighted } \\
\hline & $\mathrm{R}$ & MBE & $\mathrm{R}$ & MBE & $\mathrm{R}$ & MBE & $\mathrm{R}$ & MBE \\
\hline \multicolumn{9}{|c|}{ Case 1a (Pure Pixel, Wet Year) } \\
\hline SL & 0.716 & 0.005 & & & 0.995 & -0.001 & & \\
\hline SiL & 0.876 & 0.007 & & & 0.999 & 0.003 & & \\
\hline CL & 0.999 & 0.001 & & & 0.999 & 0.003 & & \\
\hline \multicolumn{9}{|c|}{ Case $1 b$ (Mixed Pixel, Wet Year) } \\
\hline SL,SiL,CL & 0.816 & -0.003 & 0.640 & -0.015 & 0.996 & 0.004 & 0.992 & -0.010 \\
\hline \multicolumn{9}{|c|}{ Case $1 b$ (Mixed Pixel, Relatively Wet Year) } \\
\hline $\mathrm{SL}, \mathrm{SiL}, \mathrm{CL}$ & 0.873 & 0.009 & 0.601 & -0.016 & 0.988 & 0.000 & 0.975 & -0.003 \\
\hline \multicolumn{9}{|c|}{ Case $1 b$ (Mixed Pixel, Dry Year) } \\
\hline SL,SiL,CL & 0.813 & 0.013 & 0.468 & -0.024 & 0.983 & -0.004 & 0.969 & -0.013 \\
\hline
\end{tabular}

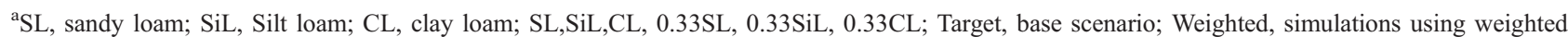
average of $\alpha, \mathrm{n}, \theta_{\text {res }}, \theta_{\text {sat }}, \mathrm{K}_{\text {sat }}$ based on area fractions of soils in the mixed-pixel; NMCGA, simulations using NMCGA-derived soil hydraulic parameters; MBE, mean bias error $\left(\mathrm{cm}^{3} \mathrm{~cm}^{-3}\right)$; R, correlation coefficient ( ).

These scenarios involved restricted/local-scale (case 3a), relatively relaxed (case $3 b$ ), and very relaxed (case $3 c$ ) soil hydraulic parameter statistics search spaces for all Mualem-van Genuchten parameters in $\mathbf{p}^{*}$ (Table 1). Cases $3 b$ and $3 c$ are attempts to define the appropriate parameter value ranges of the so-called large-scale effective soil hydraulic properties. All the simulations were conducted in a $25 \mathrm{~km} \times 25 \mathrm{~km}$ grid with an assumed soil depth of $400 \mathrm{~cm}$ and an assumed regional average seasonal groundwater table depth of $350 \mathrm{~cm}$. The large-scale crop parameters were deduced from the resampled LAI data of MODIS (Figure 6a).

[26] In summary, there were three major case studies performed to evaluate the performance of the NMCGA: case 1, using synthetic soil moisture under homogenous soils (case 1a) and heterogeneous soils (case 1b); case 2, using airborne remote sensing soil moisture; and case 3, using satellite remote sensing soil moisture.

\section{Results and Discussions}

\subsection{Case 1a: Homogeneous Soil (Pure Pixel)}

[27] A pure pixel scenario (with unique soil and land cover) was examined for the inverse modeling of nearsurface soil moisture (section 2.3.1). Although the analysis was conducted under rain-fed and irrigated conditions, the case study was straightforward for NMCGA as there were no other complexities introduced into the synthetic RS pixel. In this scenario, the time series of the "target" nearsurface $(z=0-1 \mathrm{~cm})$ soil moisture data (Figures $3 a-3 c$, Figure 4d) generated by SWAP using the "true" values of the effective soil hydraulic parameters (from the UNSODA

Table 3a. Solutions of the Noisy Monte Carlo Genetic Algorithm to Case 1a Under Wet Year Condition ${ }^{\mathrm{a}}$

\begin{tabular}{|c|c|c|c|c|c|c|c|c|}
\hline \multirow[b]{2}{*}{ Soils } & \multirow[b]{2}{*}{ Parameters } & \multirow[b]{2}{*}{ Target $^{\mathrm{b}}$} & \multicolumn{3}{|c|}{ Irrigated Condition } & \multicolumn{3}{|c|}{ Rain-Fed Condition } \\
\hline & & & Mean & SD & Sample Fitness & Mean & SD & Sample Fitness \\
\hline \multirow[t]{5}{*}{ SL } & $\alpha$ & 0.021 & 0.029 & 0.002 & & 0.027 & 0.002 & \\
\hline & $\mathrm{n}$ & 1.61 & 1.600 & 0.008 & & 1.603 & 0.000 & \\
\hline & $\theta_{\text {res }}$ & 0.067 & 0.068 & 0.004 & & 0.068 & 0.002 & \\
\hline & $\theta_{\text {sat }}$ & 0.37 & 0.370 & 0.000 & & 0.375 & 0.004 & \\
\hline & $\mathrm{K}_{\text {sat }}$ & 41.60 & 28.926 & 2.917 & 116.84 & 43.191 & 7.027 & 330.61 \\
\hline \multirow[t]{5}{*}{$\mathrm{SiL}$} & $\alpha$ & 0.012 & 0.018 & 0.004 & & 0.013 & 0.000 & \\
\hline & $\mathrm{n}$ & 1.39 & 1.382 & 0.000 & & 1.413 & 0.126 & \\
\hline & $\theta_{\text {res }}$ & 0.061 & 0.072 & 0.001 & & 0.061 & 0.000 & \\
\hline & $\theta_{\text {sat }}$ & 0.43 & 0.445 & 0.000 & & 0.451 & 0.047 & \\
\hline & $\mathrm{K}_{\text {sat }}$ & 30.50 & 36.113 & 0.046 & 51.59 & 50.824 & 2.718 & 222.80 \\
\hline \multirow[t]{5}{*}{$\mathrm{CL}$} & $\alpha^{\text {sat }}$ & 0.03 & 0.027 & 0.004 & & 0.032 & 0.000 & \\
\hline & $\mathrm{n}$ & 1.37 & 1.375 & 0.122 & & 1.420 & 0.114 & \\
\hline & $\theta_{\text {res }}$ & 0.129 & 0.121 & 0.002 & & 0.133 & 0.001 & \\
\hline & $\theta_{\text {sat }}$ & 0.47 & 0.475 & 0.000 & & 0.497 & 0.034 & \\
\hline & $\mathrm{K}_{\text {sat }}$ & 1.84 & 1.955 & 0.079 & 261.05 & 2.545 & 0.318 & 251.32 \\
\hline
\end{tabular}

\footnotetext{
${ }^{\mathrm{a}}$ Here maxgen (maximum number of generations $)=30$; npop (number of chromosomes in a generation) $=10$; nensemble $($ number of ensembles used) $=$ 3 ; nresample (how many simulations/realizations are made for each one ensemble) $=30$ per ensemble. In this example, there are three function calls (nensemble) per chromosome evaluation. Target, target parameter values; SL, sandy loam; SiL, Silt loam; CL, clay loam; $\left.\alpha\left(\mathrm{cm}^{-1}\right) ; \mathrm{n}^{(}\right) ; \theta_{\text {res }}\left(\mathrm{cm}^{3} \mathrm{~cm}^{-3}\right)$; $\theta_{\text {sat }}\left(\mathrm{cm}^{3} \mathrm{~cm}^{-3}\right) ; \mathrm{K}_{\mathrm{sat}}\left(\mathrm{cm} \mathrm{d}^{-1}\right)$. Sampling fitness is derived from equation (13).

${ }^{\mathrm{b}}$ UNSODA database [Leij et al., 1999].
} 
Table 3b. Solutions of the Noisy Monte Carlo Genetic Algorithm to Case 1b Under Wet, Relatively Wet, and Dry Year Conditions ${ }^{\text {a }}$

\begin{tabular}{|c|c|c|c|c|c|c|c|c|}
\hline \multirow[b]{2}{*}{ Soils } & \multirow[b]{2}{*}{ Parameters } & \multirow[b]{2}{*}{ Weighted $^{\mathrm{b}}$} & \multicolumn{3}{|c|}{ Irrigated Condition } & \multicolumn{3}{|c|}{ Rain-Fed Condition } \\
\hline & & & Mean & $\mathrm{SD}$ & Sample Fitness & Mean & SD & Sample Fitness \\
\hline \multicolumn{9}{|c|}{ Wet Year } \\
\hline \multirow[t]{5}{*}{ SL,SiL,CL } & $\alpha$ & 0.021 & 0.020 & 0.007 & & 0.028 & 0.001 & \\
\hline & $\mathrm{n}$ & 1.457 & 1.512 & 0.074 & & 1.404 & 0.117 & \\
\hline & $\theta_{\text {res }}$ & 0.086 & 0.082 & 0.004 & & 0.082 & 0.009 & \\
\hline & $\theta_{\text {sat }}$ & 0.423 & 0.452 & 0.049 & & 0.459 & 0.050 & \\
\hline & $\mathrm{K}_{\text {sat }}$ & 24.65 & 29.348 & 4.901 & 33.33 & 37.979 & 8.509 & 224.76 \\
\hline \multicolumn{9}{|c|}{ Relatively Wet Year } \\
\hline \multirow[t]{5}{*}{ SL,SiL,CL } & $\alpha$ & 0.021 & 0.019 & 0.007 & & 0.031 & 0.001 & \\
\hline & $\mathrm{n}$ & 1.457 & 1.402 & 0.122 & & 1.427 & 0.123 & \\
\hline & $\theta_{\text {res }}$ & 0.086 & 0.075 & 0.004 & & 0.085 & 0.014 & \\
\hline & $\theta_{\text {sat }}$ & 0.423 & 0.451 & 0.007 & & 0.449 & 0.051 & \\
\hline & $\mathrm{K}_{\text {sat }}$ & 24.65 & 30.734 & 3.625 & 38.75 & 37.554 & 7.471 & 144.87 \\
\hline \multicolumn{9}{|c|}{ Dry Year } \\
\hline \multirow{5}{*}{ SL,SiL,CL } & $\alpha$ & 0.021 & 0.019 & 0.008 & & 0.023 & 0.006 & \\
\hline & $\mathrm{n}$ & 1.457 & 1.547 & 0.014 & & 1.470 & 0.093 & \\
\hline & $\theta_{\text {res }}$ & 0.086 & 0.103 & 0.015 & & 0.084 & 0.009 & \\
\hline & $\theta_{\text {sat }}$ & 0.423 & 0.532 & 0.007 & & 0.460 & 0.043 & \\
\hline & $\mathrm{K}_{\mathrm{sat}}$ & 24.65 & 51.840 & 2.648 & 37.13 & 28.814 & 3.874 & 122.35 \\
\hline
\end{tabular}

${ }^{\mathrm{a}}$ Here maxgen $=30 ;$ npop $=10$; nensemble $=3$; nresample $=30$ per ensemble. In this example, there are three function calls (nensemble) per chromosome evaluation.

${ }^{\mathrm{b}}$ Weighted, weighted average parameter values based on area fractions of soils in the mixed-pixel.

database [Leij et al., 1999]) were used to condition the stochastic chromosome $\mathbf{p}^{*}$ (section 2.2) during the parameter estimation.

[28] Table 2 shows a summary of the performance of the effective soil hydraulic parameters (Tables $3 \mathrm{a}$ and $3 \mathrm{~b}$ ) derived by NMCGA for the pure pixel (case 1a) and mixedpixel experiments (case 1b). Apparently, for the pure pixel case, clay loam soil was almost matched perfectly under both the irrigated and rain-fed conditions with very little mean bias errors (Table 2, Figures $7 \mathrm{a}$ and $7 \mathrm{~b}$ ). This result corroborates the findings of Ines and Mohanty [2008a] suggesting that clay loam soils can be easily identifiable by inverse modeling using genetic algorithms (Figures 7c and 7d). In contrast, the results for sandy loam and silt loam under irrigated condition were found to be more inferior to that of clay loam soil. Under the rain-fed condition, however, the sandy loam and silt loam results were exceptionally better than that of the irrigated condition (Table 2). The reductions in correlations $(\mathrm{R})$ under the irrigated condition in the case of sandy loam and silt loam were largely attributed to the variability of irrigation scheduling/timing made by SWAP for various combinations of the effective soil hydraulic parameters generated during Monte Carlo (MC) resampling. On the basis of our observations, we further suggest that the underestimation or overestimation of the effective $\mathrm{K}_{\text {sat }}$ values for sandy loam/silt loam (i.e., including $\alpha$ and $\theta_{\text {res }}$ in silt loam soil) in the irrigated condition (Table $3 a$ ) had the most profound effect in correlation reductions and could affect to the proper simulation of fluxes in the subsurface. In the SWAP forward simulations, we used a dynamic irrigation scheduling criterion based on the allowable crop water stress which is very sensitive to the individual combinations of $\left\{\alpha, \mathrm{n}, \theta_{\text {res }}, \theta_{\text {sat }}, \mathrm{K}_{\mathrm{sat}}, \lambda\right\}$ even if these parameter combinations are within the bounds of a specific soil textural class. Obviously, this compounding effect is not evident in the rain-fed condition as there are no irrigation activities conducted in thi

(Figure 7b).
[29] Overall, the NMCGA effective parameter estimation scheme worked exceptionally well for case 1a (Table 3a) considering that the maximum number of generations was only 30 as compared with a similar performance for 500 generations used by Ines and Mohanty [2008a] using the modified-microGA. Most of the effective soil hydraulic parameters were estimated well (Table 3a) including their uncertainties stipulated by the simulated/estimated $\theta(\mathrm{z}, \mathrm{t})$, $\theta(\mathrm{h})$, and $\mathrm{K}(\mathrm{h})$ (Figure 7) signifying the robustness of the NMCGA for the inverse modeling of near-surface soil moisture under the pure pixel scenario both irrigated and rain-fed conditions.

\subsection{Case 1b: Heterogeneous Soil (Mixed Pixel)}

[30] The case of a mixed-pixel (i.e., multiple soils with unique land cover) under two different water management practices (irrigated versus rain-fed) was examined to test further the robustness of the newly developed NMCGA in parameter conditioning. In this case, the "target" soil moisture signatures were derived by aggregating the generated soil moisture for different soils in case 1a (Figures $3 a-3 c$, Figure 4d) based on their area fractions contained within the mixed pixel. We conducted several mixed-pixel experiments comprising different soil textural combinations (in terms of area fractions).

[31] We compare the performance of the NMCGAderived parameters and by simple weighted averaging to represent the effective values in the pixel (Table 2). The term "weighted" indicates a simulation wherein the effective soil hydraulic parameters were derived from the weighted averages of the hydraulic parameters of soils (from UNSODA) contained within the pixel. This comparison was made to test the veracity of the common practice in hydrologic/climatic modeling of averaging soil hydraulic parameters to account for heterogeneity of soils encompassed in a RS pixel or climate model grid relative to stochastic inverse parameter estimation. In this paper, we 

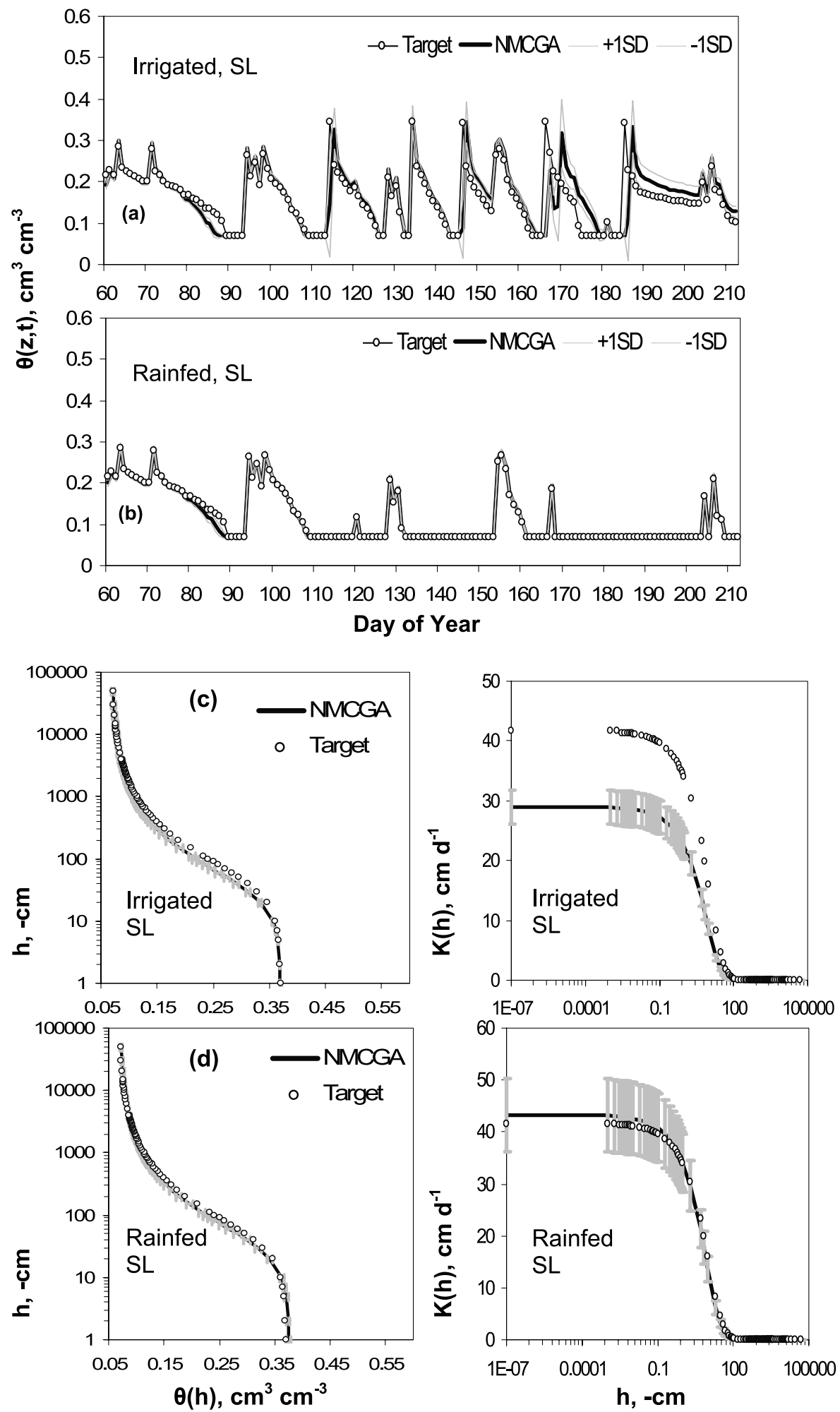

Figure 7. Sample NMCGA solutions (under wet year condition) for $\theta(\mathrm{z}, \mathrm{t})$ (top two panels) and effective $\theta(\mathrm{h})$ (bottom left panel) and $\mathrm{K}(\mathrm{h})$ (bottom right panel) from MC simulations (posterior) for a pure pixel (a and c) irrigated sandy loam (SL) and (b and d) rain-fed SL. Target, target curve; NMCGA, estimated curve by NMCGA.

present only the results of the simplest case wherein the three soils considered, sandy loam (SL), silt loam (SiL), and clay loam (CL), have equal area fractions in the pixel. Results showed that un in-fed conditions the Monte
Carlo simulations performed only slightly better than simulations using weighted averaging of the soil hydraulic parameters in replicating the "target" mixed soil moisture signature (Table 2, Figure $8 \mathrm{~b}$ ). This result suggests that if 

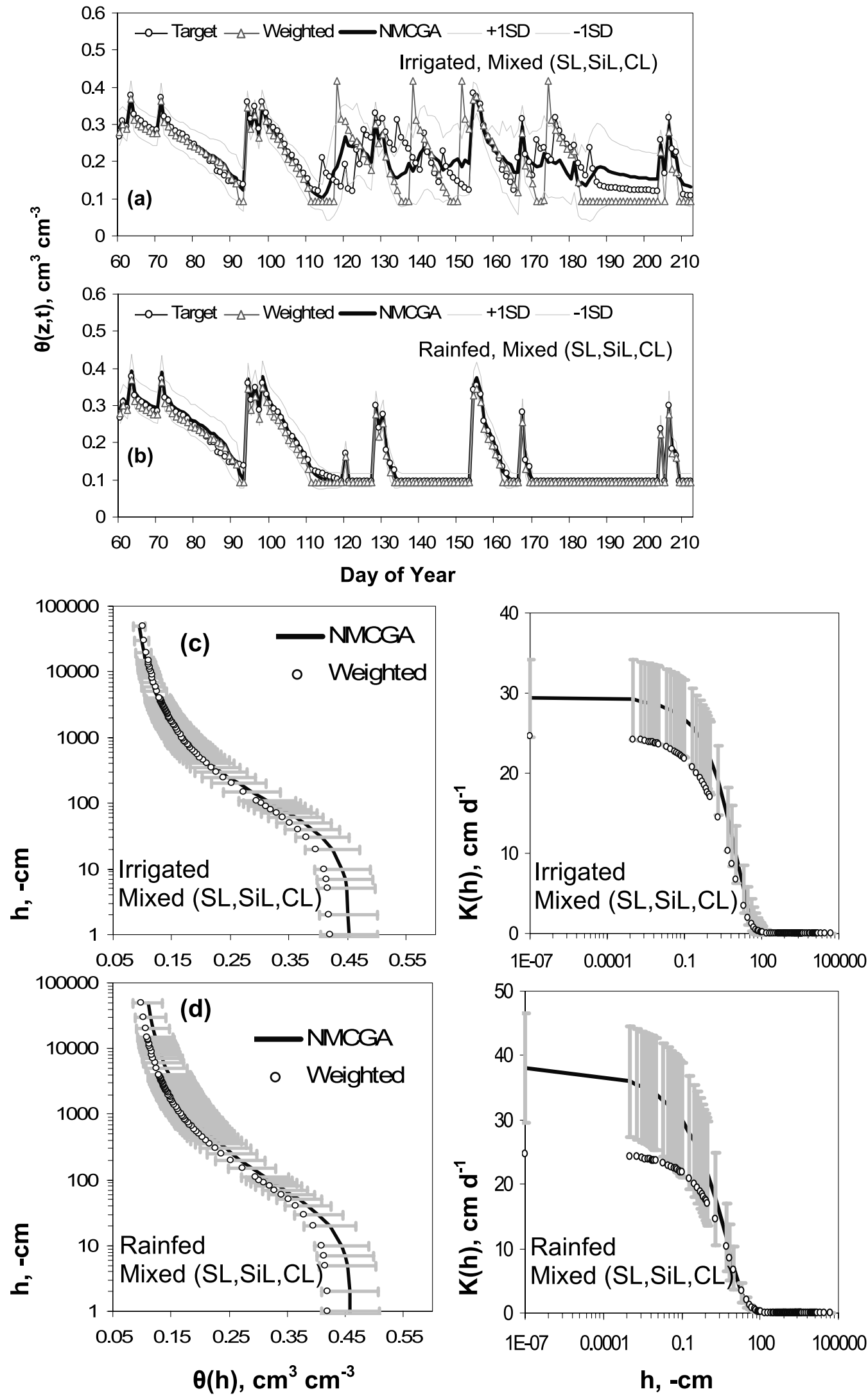

Figure 8. NMCGA solutions for $\theta(\mathrm{z}, \mathrm{t})$ (top two panels) and effective $\theta(\mathrm{h})$ (bottom left panel) and $\mathrm{K}(\mathrm{h})$ (bottom right panel) from $\mathrm{MC}$ simulations (posterior) for a mixed-pixel under wet year condition (a and c) irrigated SL,SiL,CL and (b and d) rain-fed SL,SiL,CL. Target, target curve; NMCGA, estimated by NMCGA; weighted, derived using the weighted average of the soil hydraulic parameters in the mixed-pixel. 
Table 4. NMCGA-Derived Effective Soil Hydraulic Parameters and Their Uncertainties in Selected Airborne-PSR Remote Sensing Footprints at Walnut Creek (WC) Watershed, Iowa

\begin{tabular}{llccccc}
\hline WC Sites & Statistics & $\alpha\left(\mathrm{cm}^{-1}\right)$ & $\mathrm{n}()$ & $\theta_{\text {res }}\left(\mathrm{cm}^{3} \mathrm{~cm}^{-3}\right)$ & $\theta_{\text {sat }}\left(\mathrm{cm}^{3} \mathrm{~cm}^{-3}\right)$ & 0.370 \\
WC11 & mean & 0.030 & 1.478 & 0.100 & 0.000 & $\mathrm{~K}_{\text {sat }}\left(\mathrm{cm} \mathrm{d}^{-1}\right)$ \\
& SD & 0.004 & 0.116 & 0.016 & 0.372 & 34.716 \\
WC12 & mean & 0.026 & 1.566 & 0.093 & 0.003 & 4.505 \\
& SD & 0.005 & 0.027 & 0.030 & 0.000 & 9.705 \\
WC13 & mean & 0.026 & 1.563 & 0.089 & 0.370 & 49.140 \\
& SD & 0.005 & 0.040 & 0.032 & 0.000 & 4.788 \\
WC14 & mean & 0.023 & 1.580 & 0.072 & 0.008 & 869 \\
& SD & 0.007 & 0.026 & 0.742 \\
\hline
\end{tabular}

the only source of heterogeneity in the pixel is the soil textural distribution, defining the effective parameters by weighted averaging is perhaps adequate; however, this is seldom the case in reality in which variability of land management practices within the pixel is prevalent. Nevertheless, there is an unprecedented advantage of using ensemble simulations even at this very simple modeling environment, aside from relatively higher $\mathrm{R}$ and lower mean bias error (MBE) values of the simulated soil moistures, their uncertainties are also estimated, which are not produced by using weighted averaging of parameters alone (Figure 8b).

[32] Furthermore, the robustness of the NMCGA in parameter conditioning is evident when the complexity within the pixel increases due to variability of land management practices and soil type distribution (irrigated conditions). With NMCGA, the R of simulated soil moistures remained higher with lower $\mathrm{MBE}$ values compared with the simulation results by simple parameter averaging (Table 2, Figure $8 \mathrm{a})$. Table $3 \mathrm{~b}$ shows the summary of the derived effective soil hydraulic parameters under mixed-pixel conditions (Figures $8 \mathrm{c}$ and $8 \mathrm{~d}$ ).

\subsection{Case 2: Using Airborne Remote Sensing (Polarimetric Scanned Radiometer) Soil Moisture Data}

[33] For the real-world scenario, airborne remote sensing soil moisture data were used to evaluate further the performance of the NMCGA in estimating the effective soil hydraulic parameters and its uncertainties. Here we used PSR soil moisture data (see section 2.3.2) measured during the SMEX02 hydrology campaign as criteria for conditioning the effective soil hydraulic parameters $\mathbf{p}^{*}$ of the selected airborne RS footprints (WC11, WC12, WC13, and WC14) at Walnut Creek watershed in Iowa (Figure 5a). Since the inverse modeling was also aimed at comparing the performance of the new NMCGA approach with our earlier implementation of the Dassim approach (near-surface soil moisture assimilation using the multipopulated, ensemblebased modified-microGA) (A. V. M. Ines and B. P. Mohanty, submitted manuscript, 2008), the same combinations of the initial and boundary conditions were applied in the current study. Table 4 presents the statistics of derived effective soil hydraulic parameters using the NMCGA scheme for the four airborne RS footprints.

[34] The NMCGA and Dassim schemes performed well in estimating the effective soil hydraulic parameters of the selected airborne RS footprints (Table 5). The NMCGA, however, appears to explore the parameter search spaces more efficiently because at only 30 generations it provided estimates of the effective and K(h) (Figure 10, Table 4) that honored and respected well the observed (airborne RS and in situ) soil moisture data when propagated in stochastic simulations (Figure 9). The in situ data were collected using theta probe measurements across the transects within the WC fields (see Figure 5a) during SMEX02. Relative to the Dassim scheme, the NMCGA slightly improved the MBE of the mean simulated soil moisture and the observed airborne-RS soil moisture data (Table 5). However, no apparent improvements in correlations (R) were observed. Also, only slight improvements were observed in matching the areal average in situ soil moisture data (Table 5).

[35] Furthermore, the NMCGA better captured the measured average soil hydrologic property of the selected airborne-RS footprints (B. P. Mohanty, Soil hydraulic properties of SGP97 and SMEX02 experimental sites, unpublished data, 2006) than by only averaging the hydraulic parameters (from UNSODA) of soils dominant in the pixel (Figure 10). This is interesting to note because it highlights the importance of using actual field data for estimating the effective soil hydraulic properties of larger hydrologic domains. In addition, it further supports the utility of regional inverse modeling for soil hydraulic parameter estimation at the footprint scale.

\subsection{Case 3: Using Satellite-Borne AMSR-E Soil Moisture Data}

[36] The noisy Monte Carlo genetic algorithm was evaluated using AQUA-AMSR-E soil moisture data as condi-

Table 5. Performance ( $\mathrm{R}()$ and $\left.\mathrm{MBE}\left(\mathrm{cm}^{3} \mathrm{~cm}^{-3}\right)\right)$ of the NMCGA (as Compared With Dassim) in Replicating the Target Near-Surface $(\mathrm{z}=0-5 \mathrm{~cm})$ Soil Moisture of Selected Airborne-PSR Remote Sensing Footprints at Walnut Creek Watershed, Iowa ${ }^{a}$

\begin{tabular}{|c|c|c|c|c|c|c|c|c|}
\hline \multirow[b]{3}{*}{ WC Sites } & \multicolumn{4}{|c|}{ NMCGA } & \multicolumn{4}{|c|}{ Dassim } \\
\hline & \multicolumn{2}{|c|}{$\begin{array}{l}\text { Simulated } \\
\text { Versus PSR }\end{array}$} & \multicolumn{2}{|c|}{$\begin{array}{l}\text { Simulated } \\
\text { Versus } \\
\text { Ground }\end{array}$} & \multicolumn{2}{|c|}{$\begin{array}{l}\text { Simulated } \\
\text { Versus PSR }\end{array}$} & \multicolumn{2}{|c|}{$\begin{array}{l}\text { Simulated } \\
\text { Versus } \\
\text { Ground }\end{array}$} \\
\hline & $\mathrm{R}$ & MBE & $\mathrm{R}$ & MBE & $\mathrm{R}$ & MBE & $\mathrm{R}$ & MBE \\
\hline WC11 & 79 & 0.003 & 0.9 & -0.0 & 0.80 & 0.005 & 0.97 & -0.0 \\
\hline WC & 0.76 & 0.007 & 0.93 & 0.081 & 0.77 & 0.012 & 0.92 & 0.093 \\
\hline WC13 & 0.76 & 0.021 & 0.93 & 0.002 & 0.76 & 0.019 & 0.93 & 0.001 \\
\hline WC14 & 0.75 & 0.013 & 0.90 & 0.021 & 0.75 & 0.019 & 0.89 & 0.029 \\
\hline
\end{tabular}

${ }^{a}$ NMCGA, noisy Monte Carlo genetic algorithm; Dassim, multipopulated, ensemble-based modified microGA [Ines and Mohanty, 2008a, 2008b]; Simulated, simulated mean soil moisture using NMCGA/Dassimderived parameters; PSR, observed soil moisture from polarimetric scanning radiometer; Ground, regional in situ soil moisture data. 

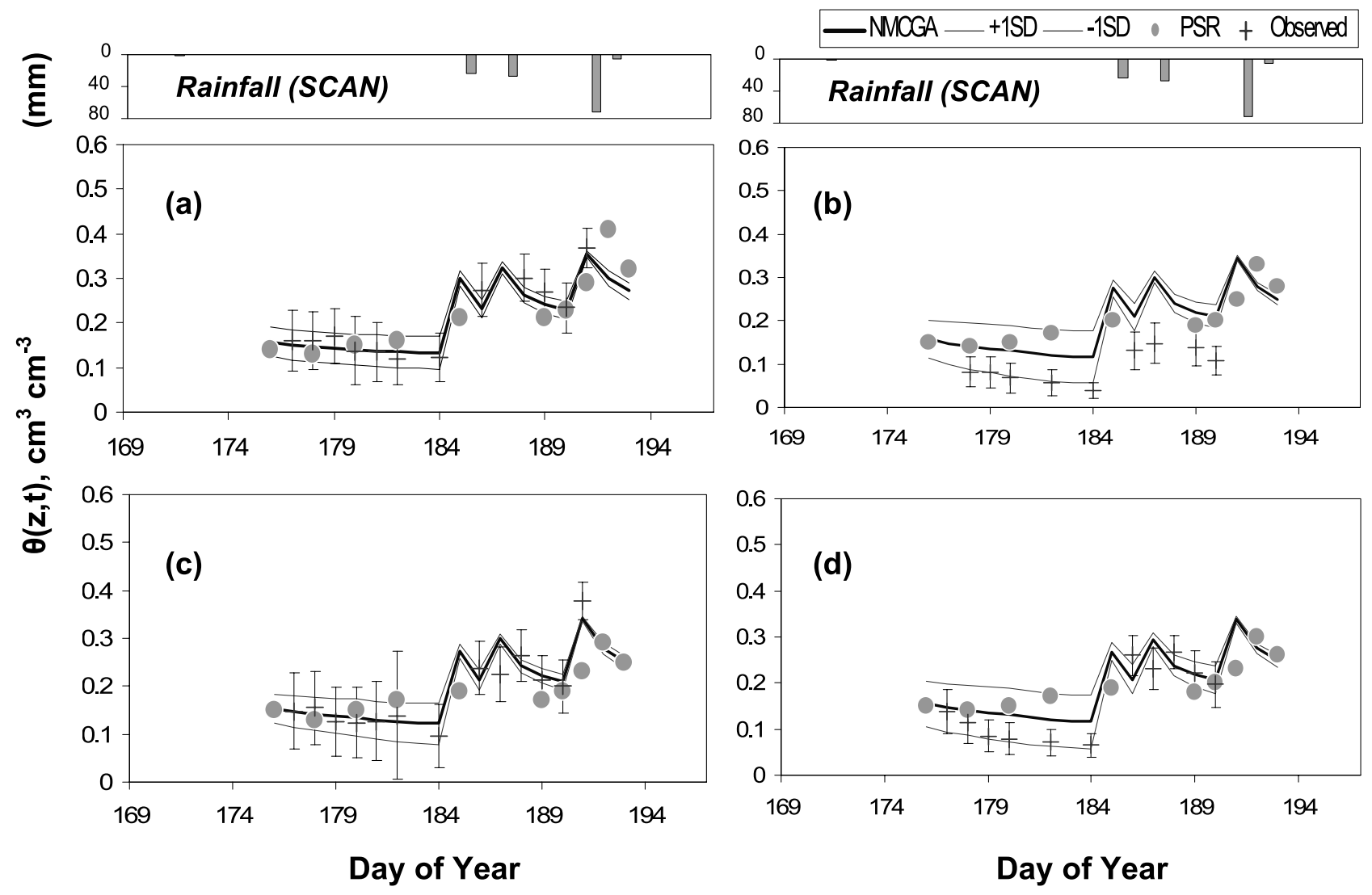

Figure 9. NMCGA solutions for $\theta(\mathrm{z}, \mathrm{t})$ from $\mathrm{MC}$ simulations (posterior) for selected Walnut Creek watershed fields (a) WC11, (b) WC12, (c) WC13, and (d) WC14.

tioning criteria for estimating the effective soil hydraulic parameters $\mathbf{p}^{*}$ at the satellite RS footprint over the Walnut Creek watershed in Iowa (Figure 6b) during the SMEX05 hydrology campaign. As discussed before, the entire SWAP model input data and meteorological forcings used here were assumed to be regional in nature, e.g., MODISLAI, TRMM-precipitation, AMSR-E soil moisture, etc. (Figures 6a and 6b). Note that the TRMM precipitation data were used as is (i.e., no filtering done) in the application, and its correspondence with AMSR-E soil moisture was not evaluated or cross checked beforehand to ultimately test TRMM's suitability as a source of rainfall data for large-scale hydroclimatic modeling. Obviously, more cross validation of TRMM and AMSR-E relationships should be done before any other applications beyond experimental purposes.

[37] Figure 11 summarizes the results of the NMCGA considering the scenarios $3 \mathrm{a}, 3 \mathrm{~b}$, and $3 \mathrm{c}$ (Table 1; section 2.3.2). Case $3 \mathrm{a}$ assumes that the soil hydraulic parameters from UNSODA are effective at the point or local scale. It is evident from Figure 11a that the NMCGA attempted to scale down the $\theta_{\text {sat }}$ to better match the AMSR-E soil moisture data (Figure 12a). However, the restricted GA parameter spaces (Table 1) did not allow the NMCGA to further improve the matching of the SWAP simulated soil moisture with AMSR-E data. For comparison, the texture-based $\theta(\mathrm{h})$ and $\mathrm{K}(\mathrm{h})$ of clay loam from UNSODA and actual point-scale soil hydraulic properties derived from WC11 field [see Ines and Mohanty, 2008b] were superimposed on the NMCGAestimated effective hydra observed that except for UNSODA, the point-scale-derived soil hydraulic parameters correspond well with the NMCGA results constrained on known point-scale value ranges of the soil hydraulic parameters (Figure 11a). However, these effective soil hydraulic parameters did not match well the soil moisture data between DOY 41 and 81 (Figure 12a). As an attempt to define the appropriate parameter domain for large-scale soil hydraulic parameters, we slightly relaxed the statistical properties of the parameters $n$ and $K_{\text {sat }}$ (case $3 b$, Table 1) and found some improvements in matching AMSR-E and simulated largescale soil moisture (Figure 12b). The spread of the effective $\theta(\mathrm{h})$ curve at the drier end became more prominent due to the more flexible/variable $\mathrm{n}$ parameter values (Table 6). Finally, by relaxing fully all of the effective soil hydraulic parameter statistics (case 3c, Table 1), a slightly better fit of the AMSR-E soil moisture data (Figure 12c, Table 7) was observed than the results for cases $3 \mathrm{a}$ and $3 \mathrm{~b}$ (compare DOY 41-81; Figure 12). Figure 11c suggests that the scale parameter $\theta_{\text {sat }}$ needed to be rescaled to its minimum possible value in order to match better (on the average) the largescale AMSR-E soil moisture data (Figure 12c). Interesting to note is that the effective soil hydraulic function scaling hypothesis postulated in Figure 1 (mean values reduce with increasing support) appears to manifest in the AMSR-E results (compare Figures 11a, 11b, and 11c), although further study is required to fully test its validity.

[38] Table 6 also shows the corresponding values of the effective soil hydraulic parameters and their uncertainties by NMCGA for the three cases (3a, 3b, and 3c). Although 

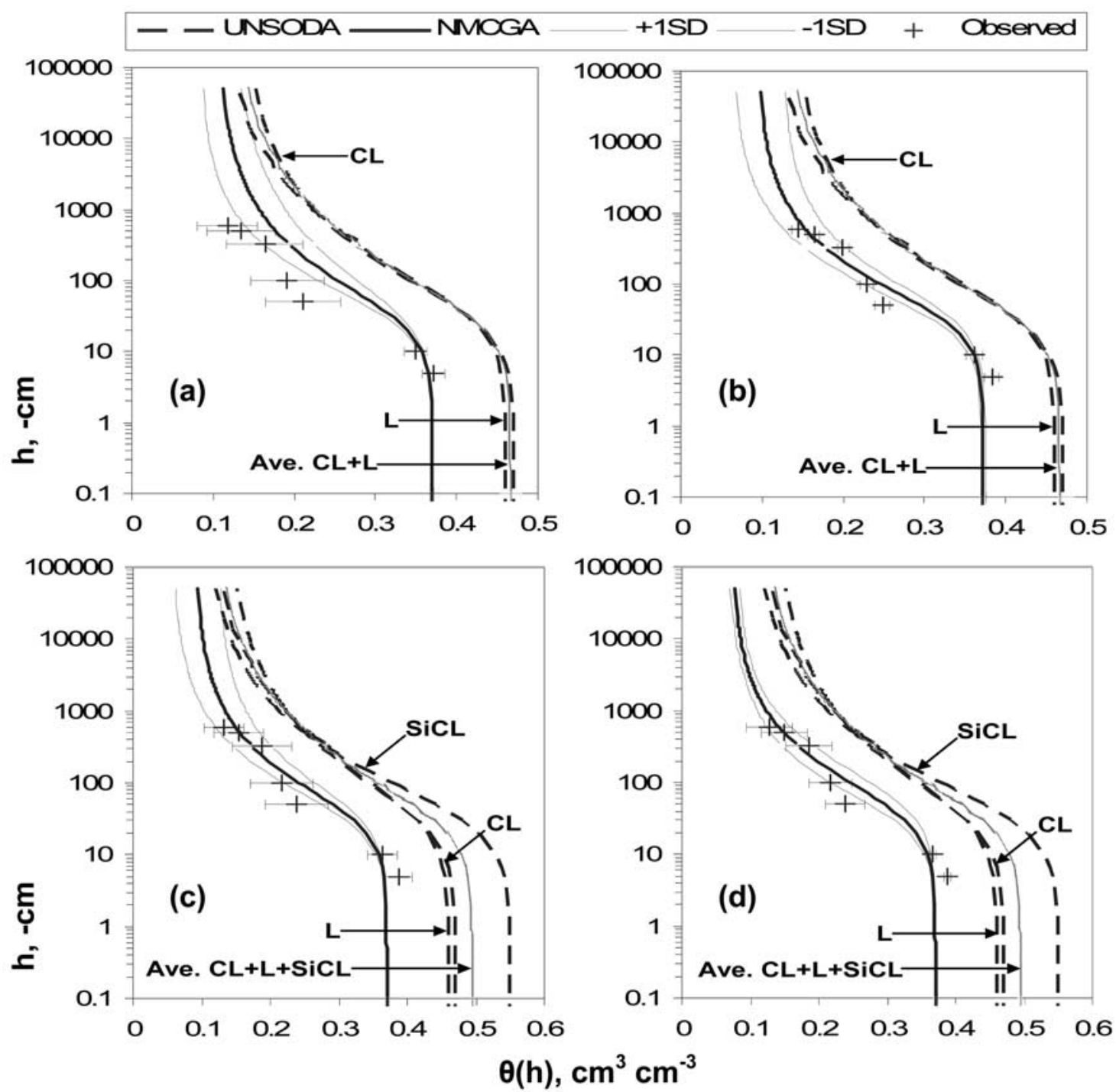

Figure 10. NMCGA solutions for effective $\theta(\mathrm{h})$ from $\mathrm{MC}$ simulations (posterior) for selected Walnut Creek watershed fields (a) WC11, (b) WC12, (c) WC13, and (d) WC14.

Figure 11 showed the progressive reduction tendency of the effective soil water retention function $\theta(\mathrm{h})$, it was not true for all the constituent parameters. The shape parameter $\alpha$ tends to increase its mean value with an increasing spread/ standard deviation. A similar pattern was also observed with the other shape parameter $\mathrm{n}$. The scale parameters $\theta_{\text {res }}, \theta_{\text {sat }}$, and $\mathrm{K}_{\mathrm{sat}}$ showed mixed results. The scaling down effect due to process and scale aggregations within the AMSR E soil moisture data is most profound in the scale parameter $\theta_{\text {sat }}$ (Figures 11c and 12c). The reduction of $\mathrm{K}_{\text {sat }}$ from case $3 \mathrm{a}$ to case $3 \mathrm{c}$ was also observed, although this reduction was not as major as of the $\theta_{\text {sat, }}$ suggesting that scale parameter $\mathrm{K}_{\text {sat }}$ may not be sensitive any further at this spatial scale (compare Figure 11a with 11c). The parameter $\theta_{\text {res }}$ had mixed results; its mean value did not show increasing or decreasing trend across cases $3 a-3 c$, whereas its spread appeared to increase as the effective parameter statistical properties were relaxed progressively in the solutions (Table 1). This result suggests that the definition of the point-scale data range as used in the scale parameter $\theta_{\text {res }}$ was enough to describe the driest event in the time serie
(Figure 6b, Figure 12). The correlations of the simulated large-scale soil moisture and AMSR-E soil moisture, however, remained small due to the significant mismatch between TRMM rainfall pattern and the AMSR-E soil moisture data. Because of this mismatch in rainfall and AMSR-E soil moisture, SWAP was not able to simulate properly the drydown from DOY 261-300, affecting the correlation between the simulated and observed RS soil moisture data. Table 7 suggests that by relaxing the GA search spaces to the maximum possible soil hydraulic parameter ranges (Table 1), it could further improve the mean absolute errors (which may be associated in part to scale) of the simulated and observed near-surface soil moistures.

\section{Concluding Remarks}

[39] In this paper, we developed and tested a scaledependent parameter estimation scheme, noisy Monte Carlo genetic algorithm (NMCGA), based on the concept of parameter conditioning and the framework of noisy genetic 

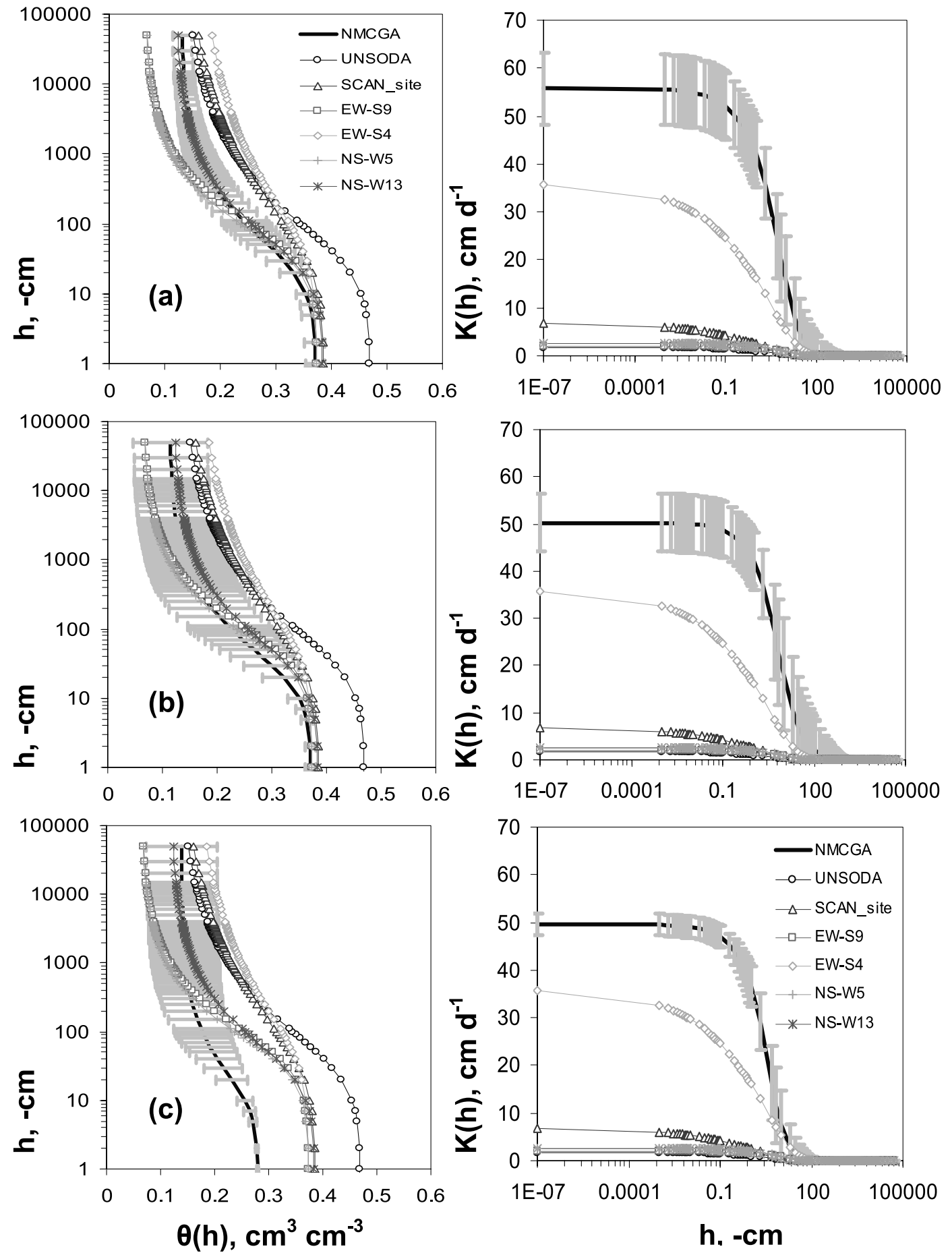

Figure 11. NMCGA solutions for effective $\theta(h)$ and effective $K(h)$ from $M C$ simulations (posterior) for AMSR-E pixel at Walnut Creek watershed, Iowa: (a) case 3a, (b) case 3b, and (c) case 3c scenarios. UNSODA indicates texture-based clay loam; NS, EW, and SCAN sites are derived point scale soil hydraulic properties from the AMSR-E footprint (at WC11 field; see Ines and Mohanty [2008b]).

algorithms. First, we tested the NMCGA with hypothetical remote sensing (RS) pixels under pure or mixed soil and land cover conditions. The NMCGA performed well in both homogeneous and heterogeneous pixel conditions. Even with the complexities introduced into the pixel due to variability of simulated land management practices under the mixed-pixel scenarios, the NMCGA gave better results than that of the weight

eraging of soil hydraulic parameters for describing the effective (soil hydraulic) parameters and their uncertainties. The NMCGA was tested further using airborne RS soil moisture data as conditioning criteria for the inverse analysis and was compared with the previous implementation of Dassim [Ines and Mohanty, 2008a, submitted manuscript, 2008] in the same study area (Walnut Creek watershed, Iowa). The results showed that the NMCGA explored the parameter search spaces more 

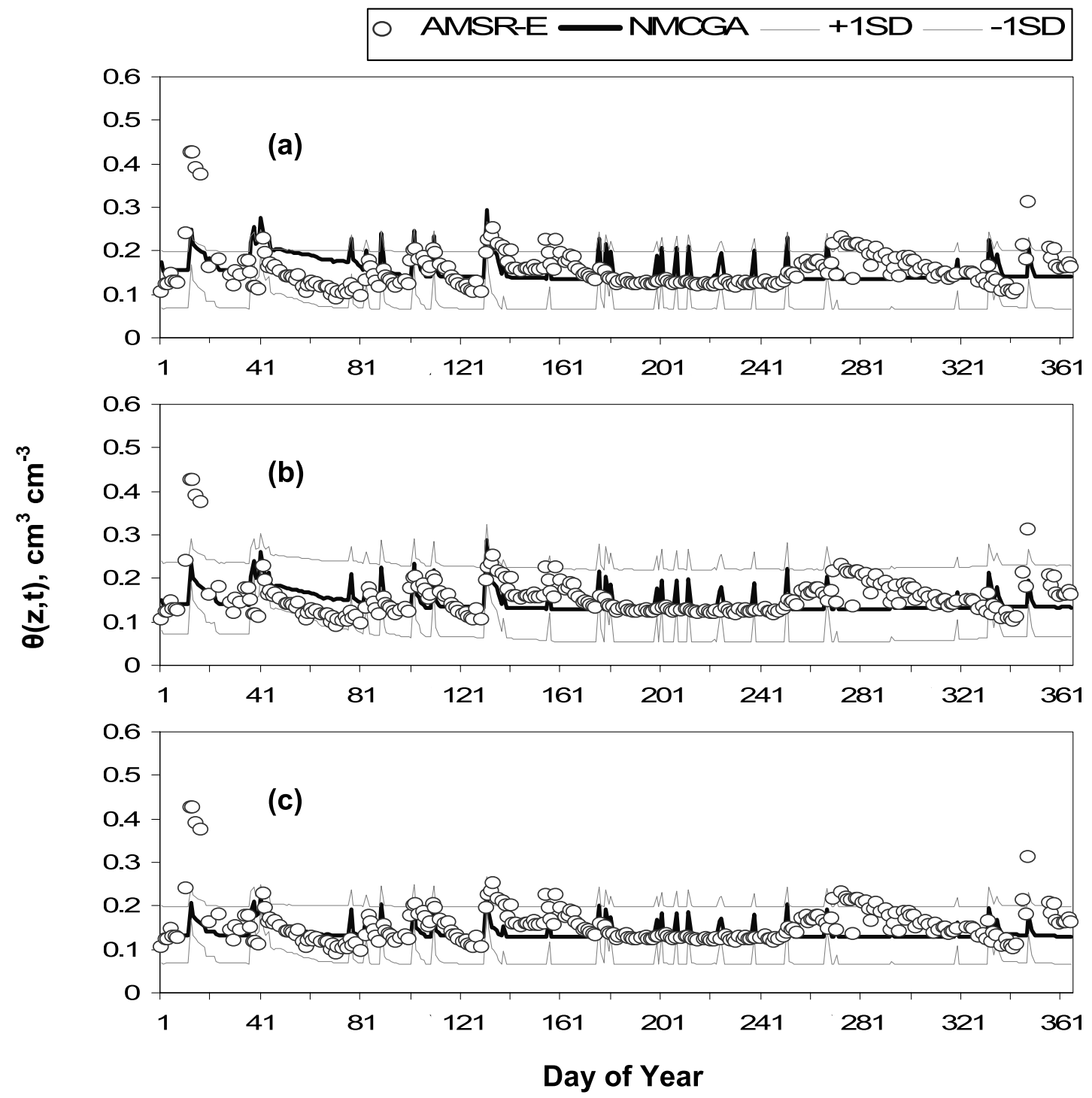

Figure 12. NMCGA solutions for $\theta(z, t)$ from MC simulations (posterior) for AMSR-E pixel at Walnut Creek watershed, Iowa: (a) case $3 a$, (b) case $3 b$, and (c) case $3 c$ scenarios.

efficiently (at a lower number of generations) but performed comparably with Dassim in estimating the effective soil hydraulic functions of the selected airborne RS footprints. Last, we tested the NMCGA using soil moisture data from the Aqua AMSR-E satellite. We found that fully relaxing the search spaces of the effective parameter statistics beyond the known point-scale value ranges resulted in a better matching between the simulated soil moisture and observed AMSR-E soil moisture data. As we relaxed the search parameter statistics range progressively (Table 1), the validity of the postulated effective soil hydraulic function scaling hypothesis (concept depicted in Figure 1) was observed (Figure 11). The scaling effect was most profound for $\theta_{\text {sat }}$ among other Mualem-van Genuchten soil hydraulic parameters.

Table 6. Derived Effective Soil Hydraulic Parameters and Their Uncertainties of the Selected AMSR-E Footprint at Walnut Creek Watershed, Iowa ${ }^{\mathrm{a}}$

\begin{tabular}{|c|c|c|c|c|c|c|}
\hline $\begin{array}{c}\text { AMSR-E } \\
\text { Case Studies }\end{array}$ & Statistics & $\alpha\left(\mathrm{cm}^{-1}\right)$ & $\mathrm{n}()$ & $\theta_{\text {res }}\left(\mathrm{cm}^{3} \mathrm{~cm}^{-3}\right)$ & $\theta_{\text {sat }}\left(\mathrm{cm}^{3} \mathrm{~cm}^{-3}\right)$ & $\mathrm{K}_{\mathrm{sat}}\left(\mathrm{cm} \mathrm{d}^{-1}\right)$ \\
\hline \multirow[t]{2}{*}{ Case 3a } & mean & 0.036 & 1.600 & 0.127 & 0.370 & 54.978 \\
\hline & SD & 0.019 & 0.000 & 0.017 & 0.019 & 7.440 \\
\hline \multirow[t]{2}{*}{ Case $3 b$} & mean & 0.041 & 1.747 & 0.117 & 0.370 & 49.623 \\
\hline & SD & 0.026 & 0.031 & 0.068 & 0.009 & 6.258 \\
\hline \multirow[t]{2}{*}{ Case $3 c$} & mean & 0.075 & 1.739 & 0.130 & 0.280 & 49.197 \\
\hline & SD & 0.034 & 0.064 & 0.068 & 0.000 & 2.265 \\
\hline
\end{tabular}

${ }^{\text {a }}$ See section 2.3.2 for descri f the specific cases. 
Table 7. Performance of the NMCGA in Replicating the Target Near-Surface $(\mathrm{z}=0-1 \mathrm{~cm})$ Soil Moisture of the Selected AMSR-E Footprint at Walnut Creek Watershed, Iowa

\begin{tabular}{lccc}
\hline & \multicolumn{3}{c}{ Simulated Versus RS } \\
\cline { 2 - 4 } $\begin{array}{c}\text { AMSR-E } \\
\text { Case Studies }\end{array}$ & $\mathrm{R}$ & $\mathrm{MBE}$ & MAE \\
\hline Case 3a & 0.22 & 0.002 & 0.036 \\
Case 3b & 0.26 & -0.008 & 0.033 \\
Case 3c & 0.28 & -0.015 & 0.031 \\
\hline
\end{tabular}

[40] However, soil hydraulic properties at the near-surface may not be always representative of the subsurface unless the soil profile is really homogenous. Ines and Mohanty [2008a, 2008b] showed that effective soil hydraulic parameters derived from the near-surface $(0-$ $6 \mathrm{~cm}$ ) are applicable to some degree in representing the soil hydrologic processes in the subsurface, but under highly heterogeneous soils they are less successful. It is recommended that additional information (if available), e.g., deeper layer soil moisture data and evapotranspiration from $\mathrm{RS}$, should be used in addition to the near-surface soil moisture to characterize better the effective soil hydraulic properties of the deeper layers of the soil profile. Because the presented inverse modeling method in this paper is generic, including these additional conditioning data is not a big problem. In this current study the reason why we used near-surface soil moisture is to explore the utility of remotely sensed soil moisture (which are shallow in depth) for characterizing the effective soil hydraulic properties in a footprint.

[41] There is room for improvements of the current method, and there are fertile grounds for future research, e.g., exploring the effects of model structure uncertainties (both soil-hydrologic model and soil hydraulic constitutive functions) to the derived effective soil hydraulic properties, and the validation of these derived properties in predicting other actual hydrologic processes (e.g., evapotranspiration, runoff, percolation) aside from soil moisture. Further validation of the postulated scaling hypothesis is needed to study the effects of other factors that could be contributing to the scaling behavior of the soil hydraulic properties at different support/extent.

[42] Nevertheless, we found the noisy Monte Carlo genetic algorithm (NMCGA) framework to be promising for the inverse modeling (IM)-based near-surface RS soil moisture assimilation for estimating the effective soil hydraulic parameters and their uncertainties at a remote sensing footprint or climate model grid scale. This opens up avenues for estimating the effective soil hydraulic parameters for the continental United States or more ambitiously at the global scale using a combination of available global RS data sets and observed/reanalysis climate forcings aggregated/resampled at the particular scales of interests.

[43] Acknowledgments. The research was funded by NASA-GAPP and NASA-THP grants. We would like to acknowledge the partial support of LANL-SAHRA, and NSF (CMG/DMS grant) for this work. We also acknowledge the assistance of Narendra Das of the Department of Biological and Agricultural Engineering, Texas A\&M University, in the collection of the satellite remote sensing data used in this study. We sincerely thank the editors and three anonymous reviewers for helping us improve the quality of this paper.

\section{References}

Abbaspour, K. C., M. T. Van Genuchten, R. Schulin, and E. Schläppi (1997), A sequential uncertainty domain inverse procedure for estimating subsurface flow and transport parameters, Water Resour. Res., 33, 18791892, doi:10.1029/97WR01230.

Abbaspour, K. C., M. A. Sonnleitner, and R. Schulin (1999), Uncertainty in estimation of soil hydraulic parameters by inverse modeling: Example lysimeter experiments, Soil Sci. Soc. Am. J., 63, 501-509.

Bates, B. C., and E. P. Campbell (2001), A Markov chain Monte Carlo scheme for parameter estimation and influence in conceptual rainfallrunoff modeling, Water Resour. Res., 37, 937-947, doi:10.1029/ 2000WR900363.

Bertuzzi, P., and L. Brucker (1996), A scaling based estimation of soil unsaturated hydraulic properties at a field scale, Irrig. Sci., 17, 23-30, doi:10.1007/s002710050018.

Beven, K., and A. Binley (1992), The future of distributed models: Model calibration and uncertainty predictions, Hydrol. Processes, 6, 279-298, doi:10.1002/hyp.3360060305.

Beven, K. J., and J. Freer (2001), Equifinality, data assimilation, and uncertainty estimation in mechanistic modelling of complex environmental systems using the GLUE methodology, J. Hydrol., 249, 11-29, doi:10.1016/S0022-1694 (01)00421-8.

Bindlish, R. (2004), SMEX02 aircraft polarimetric scanning radiometer (PSR) Tb data, Natl. Snow and Ice Data Cent., Boulder, Colo.

Brantley, S. L., et al. (2006), Frontiers in exploration of the critical zone: Report of a workshop sponsored by the National Science Foundation (NSF), 30 pp., Newark, De., 24-26 Oct.

Brooks, R. H., and A. T. Corey (1966), Properties of the porous media affecting fluid flow, J. Irrig. Drain. Div. Am. Soc. Civ. Eng., 92, 61-88.

Burke, E., R. Gurney, L. Simmonds, and P. O'Neill (1998), Using a modeling approach to predict soil hydraulic properties from passive microwave measurements, IEEE Trans. Geosci. Remote Sens., 36, 454-462, doi:10.1109/36.662729.

Campbell, G. S. (1974), A simple method for determining unsaturated conductivity from moisture retention data, Soil Sci., 117, 311-314, doi:10.1097/00010694-197406000-00001.

Chan-Hilton, A. B., and T. B. Culver (2000), Constraint handling for genetic algorithms in optimal remediation design, J. Water Resour. Plann. Manage., 125, 128-137, doi:10.1061/(ASCE)0733-9496(2000)126: 3(128).

Chemin, Y., and K. Honda (2006), Spatio-temporal fusion of rice actual evapotranspiration with genetic algorithms and an agro-hydrological model, IEEE Trans. Geosci. Remote Sens., 44, 3462-3469, doi:10.1109/TGRS.2006.879111.

Clausnitzer, V., J. W. Hopmans, and D. R. Nielsen (1992), Simultaneous scaling of soil water retention and hydraulic conductivity curves, Water Resour. Res., 26, 1483-1496.

Crow, W. T., D. Ryu, and J. S. Famiglietti (2005), Upscaling of field-scale soil moisture measurements using distributed land surface modeling, $A d v$. Water Resour, 28, 1-14, doi:10.1016/j.advwatres.2004.10.004.

Droogers, P., and W. G. M. Bastiaanssen (2002), Irrigation performance using hydrological and remote sensing modeling, J. Irrig. Drain. Eng., 128, 11-18, doi:10.1061/(ASCE)0733-9437(2002)128:1(11).

Drusch, M., E. F. Wood, and C. Simmer (1999), Up-scaling effects in passive microwave remote sensing: ESTAR $1.4 \mathrm{GHz}$ measurements during SGP '97, Geophys. Res. Lett., 26, 879-882, doi:10.1029/ 1999GL900150.

Duan, Q. Y., S. Sorooshian, and H. V. Gupta (1992), Effective and efficient global optimization for conceptual rainfall-runoff models, Water Resour. Res., 28, 1015-1031, doi:10.1029/91WR02985.

Efron, B. (1982), The Jackknife, the Bootstrap and Other Resampling Plans, Reg. Conf. Ser. Appl. Math., 92 pp., Soc. for Ind. and App. Math., Philadelphia, Pa.

Feddes, R. A., G. H. De Rooij, J. C. Van Dam, P. Kabat, and P. Droogers (1993a), Estimation of regional effective soil hydraulic parameters by inverse modeling, in Water Flow and Solute Transport in Soils, Adv. Ser. Agric. Sci., edited by D. Russo and G. Dagan, pp. 211-233, Springer, Berlin.

Feddes, R. A., M. Menenti, P. Kabat, and W. G. M. Bastiaanssen (1993b), Is large-scale inverse modeling of unsaturated flow with areal average evaporation and surface soil moisture as estimated by remote sensing feasible?, J. Hydrol., 143, 125-152, doi:10.1016/0022-1694(93) 90092-N. 
Goldberg, D. E. (1989), Genetic Algorithms in Search and Optimization and Machine Learning, Addison-Wesley, Boston, Mass.

Gomez-Hernandez, J. J., and S. M. Gorelick (1989), Effective groundwater model parameter values: Influence of spatial variability of hydraulic conductivity, leakage, and recharge, Water Resour. Res., 25, 405-419, doi:10.1029/WR025i003p00405.

Gopalakrishnan, G., B. S. Minsker, and D. E. Goldberg (2003), Optimal sampling in a noisy genetic algorithm for risk-based remediation design, J. Hydroinf., 5, 11-25.

Green, T. R., J. E. Contantz, and D. L. Freyberg (1996), Upscaled soil water retention using van Genutchten's function, J. Hydrol. Eng., 1, 123-130, doi:10.1061/(ASCE)1084-0699(1996)1:3(123).

Haertel, V. F., and Y. E. Shimabukuro (2005), Spectral linear mixing model in low spatial resolution image data, IEEE Trans. Geosci. Remote Sens., 43, 2555-2562, doi:10.1109/TGRS.2005.848692.

Holland, J. H. (1975), Adaptation in Natural and Artificial Systems, Univ. of Mich. Press, Ann Arbor.

Hopmans, J. W., and J. N. M. Stricker (1989), Stochastic analysis for soil water regime in a watershed, J. Hydrol., 105, 57-84, doi:10.1016/00221694(89)90096-6.

Ines, A. V. M., and P. Droogers (2002), Inverse modelling in estimating soil hydraulic functions: A genetic algorithm approach, Hydrol. Earth Syst. Sci., 6(1), 49-65.

Ines, A. V. M., and K. Honda (2005), On quantifying agricultural and water management practices from low spatial resolution RS data using genetic algorithms: A numerical study for mixed pixel environment, Adv. Water Resour., 28, 856-870, doi:10.1016/j.advwatres.2004.11.015.

Ines, A. V. M., and B. P. Mohanty (2008a), Near-surface soil moisture assimilation to quantify effective soil hydraulic properties using genetic algorithm: 1. Conceptual modeling, Water Resour. Res., 44, W06422, doi:10.1029/2007WR005990.

Ines, A. V. M., and B. P. Mohanty (2008b), Near-surface soil moisture assimilation to quantify effective soil hydraulic properties under different hydro-climatic conditions, Vadose Zone J., 7, 39-52, doi:10.2136/ vzj2007.0048.

Jackson, T. J., D. M. Le Vine, A. Y. Hsu, A. Oldak, P. J. Starks, C. T. Swift, J. D. Isham, and M. Hakan (1999), Soil moisture mapping at regional scales using microwave radiometry: The Southern Great Plains hydrology experiment, IEEE Trans. Geosci. Remote Sens., 37, 2136-2151, doi: $10.1109 / 36.789610$.

Jury, W. A., D. Russo, and G. Sposito (1987), The spatial variability of water and solute transport properties in unsaturated soil: II. Scaling of water transport, Hilgardia, 55, 33-56.

Kabat, P., R. W. A. Hutjes, and R. A. Feddes (1997), The scaling characteristics of soil parameters: From plot scale heterogeneity to subgrid parameterization, J. Hydrol., 190, 363-396, doi:10.1016/S00221694(96)03134-4

Korvin, G. (1982), Axiomatic characterization of the general mixture rule, Geoexploration, 19, 267-276, doi:10.1016/0016-7142(82)90031-X.

Kuczera, G., and E. Parent (1998), Monte Carlo assessment of parameter uncertainty in conceptual catchment models: Metropolis algorithm, J. Hydrol., 211, 69-85, doi:10.1016/S0022-1694(98)00198-X.

Leij, F. J., W. J. Alves, M. T. Van Genuchten, and J. R. Williams (1999), The UNSODA unsaturated soil hydraulic database, in Characterization and Measurement of the Hydraulic Properties of Unsaturated Porous Media, edited by M. T. Van Genuchten et al., pp. 1269-1281, Univ. of Calif., Riverside.

Michalewicz, Z. (1996), Genetic Algorithms + Data Structures = Evolution Programs, 3rd ed., Springer, New York.

Miller, B. L. (1997), Noise, sampling and efficient genetic algorithms, IlliGAL Rep. 97001, Ill. Genetic Algorithms Lab., Univ. of Ill. at Urbana-Champaign, May.

Miller, B. L., and D. E. Goldberg (1996), Optimal sampling for genetic algorithms, in Intelligent Engineering Systems Through Artificial Neural Networks (ANNIE '96), vol. 6, edited by C. H. Dagli et al., pp. 291-298, Am. Soc. of Mech. Eng. Press, New York.

Miller, E. E., and R. D. Miller (1956), Physical theory of capillary flow phenomena, J. Appl. Phys., 27, 324-332, doi:10.1063/1.1722370.
Mohanty, B. P., and T. H. Skaggs (2001), Spatio-temporal evolution and time-stable characteristics of soil moisture within remote sensing footprints with varying soil, slope and vegetation, Adv. Water Resour., 24, 1051 - 1067, doi:10.1016/S0309-1708(01)00034-3.

Mualem, Y. (1976), A new model for predicting the hydraulic conductivity of unsaturated porous media, Water Resour. Res., 12, 513-522, doi:10.1029/WR012i003p00513.

Njoku, E. G., T. J. Jackson, V. Lakshmi, T. K. Chan, and S. V. Nghiem (2003), Soil moisture retrieval from AMSR-E, IEEE Trans. Geosci. Remote Sens., 41, 215-229, doi:10.1109/TGRS.2002.808243.

Rockhold, M. L., R. E. Rossi, and R. G. Hills (1996), Application of similar media scaling and conditional simulation for modeling water flow and tritium transport at the Las Cruces trench Site, Water Resour. Res., 32, 595-609, doi:10.1029/95WR03398.

Shimabukuro, Y. E., and J. A. Smith (1991), The least-squares mixing models to generate fraction images derived from remote sensing multispectral data, IEEE Trans. Geosci. Remote Sens., 29, 16-20, doi:10.1109/ 36.103288 .

Smalley, J. B., B. S. Minsker, and D. E. Goldberg (2000), Risk-based in situ bioremediation design using a noisy genetic algorithm, Water Resour. Res., 36, 3043-3052, doi:10.1029/2000WR900191.

Van Dam, J. C., J. Huygen, J. G. Wesseling, R. A. Feddes, P. Kabat, P. E. V. van Waslum, P. Groenendjik, and C. A. van Diepen (1997), Theory of SWAP version 2.0: Simulation of water flow and plant growth in the soilwater-atmosphere-plant environment, Tech. Doc. 45, Wageningen Agric. Univ. and DLO Winand Staring Cent., Wageningen, Netherlands.

Van Genuchten, M. T. (1980), A closed-form equation for predicting the hydraulic conductivity of unsaturated soils, Soil Sci. Soc. Am. J., 44, $892-898$.

Vrugt, J. A., H. V. Gupta, W. Bouten, and S. Sorooshian (2003), A Shuffled Complex Evolution Metropolis algorithm for optimization and uncertainty assessment of hydrologic model parameters, Water Resour. Res., 39(8), 1201, doi:10.1029/2002WR001642.

Vrugt, J. A., C. G. H. Diks, H. V. Gupta, W. Bouten, and J. M. Verstraten (2005), Improved treatment of uncertainty in hydrologic modeling: Combining the strengths of global optimization and data assimilation, Water Resour. Res., 41, W01017, doi:10.1029/2004WR003059.

Wang, Q. J. (1991), The genetic algorithm and its application to calibrating conceptual rainfall-runoff models, Water Resour. Res., 27, 2467-2471, doi:10.1029/91WR01305.

Wood, E. F. (1994), Scaling, soil moisture and evapotranspiration in runoff models, Adv. Water Resour., 17, 24-34, doi:10.1016/0309-1708(94) 90021-3.

Wu, J., C. Zheng, C. Cien, and L. Zheng (2006), A comparative study of Monte Carlo simple genetic algorithm and noisy genetic algorithm for cost-effective sampling network design under uncertainty, Adv. Water Resour., 29, 899-911, doi:10.1016/j.advwatres.2005.08.005.

Zhu, J. T., and B. P. Mohanty (2002), Spatial averaging of Van Genuchten hydraulic parameters for steady state flow in heterogeneous soils: A numerical study, Vadose Zone J., 1, 261-272.

Zhu, J. T., and B. P. Mohanty (2003), Effective hydraulic parameters for steady state vertical flow in heterogeneous soils, Water Resour. Res., 39(8), 1227, doi:10.1029/2002WR001831.

Zhu, J. T., and B. P. Mohanty (2004), Soil hydraulic parameter upscaling for steady-state flow with root water uptake, Vadose Zone J., 3, 14641470 .

Zhu, J. T., and B. P. Mohanty (2006), Effective scaling factors for transient infiltration in heterogeneous soils, J. Hydrol., 319, 96-108, doi:10.1016/j.jhydrol.2005.07.004.

A. V. M. Ines, International Research Institute for Climate and Society, Earth Institute at Columbia University, 61 Route 9W, Palisades, NY 10964, USA.

B. P. Mohanty, Department of Biological and Agricultural Engineering, Texas A\&M University, 2117 TAMU, 201 Scoates Hall, College Station, TX 77843, USA. (bmohanty@tamu.edu) 